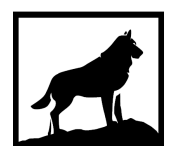

Michigan Technological

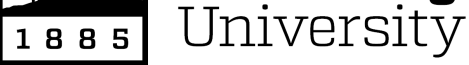

Michigan Technological University Digital Commons @ Michigan Tech

\title{
GETTING ACTIVE WITH PASSIVE CROSSINGS: INVESTIGATING THE EFFICACY OF IN-VEHICLE AUDITORY ALERTS FOR RAIL ROAD CROSSINGS
}

Steven Landry

Michigan Technological University, sglandry@mtu.edu

Copyright 2016 Steven Landry

\section{Recommended Citation}

Landry, Steven, "GETTING ACTIVE WITH PASSIVE CROSSINGS: INVESTIGATING THE EFFICACY OF INVEHICLE AUDITORY ALERTS FOR RAIL ROAD CROSSINGS", Open Access Master's Thesis, Michigan Technological University, 2016.

https://doi.org/10.37099/mtu.dc.etdr/94

Follow this and additional works at: https://digitalcommons.mtu.edu/etdr

Part of the Applied Behavior Analysis Commons, Cognition and Perception Commons, and the Cognitive Psychology Commons 
GETTING ACTIVE WITH PASSIVE CROSSINGS: INVESTIGATING THE EFFICACY OF IN-VEHICLE AUDITORY ALERTS FOR RAIL ROAD CROSSINGS

\author{
By \\ Steven Landry
}

A THESIS

Submitted in partial fulfillment of the requirements for the degree of MASTER OF SCIENCE

In Applied Cognitive Science and Human Factors

MICHIGAN TECHNOLOGICAL UNIVERSITY

2016

C2016 Steven Landry 
This thesis has been approved in partial fulfillment of the requirements for the Degree of MASTER OF SCIENCE in Applied Cognitive Science and Human Factors.

Department of Cognitive and Learning Sciences

Thesis Advisor: Dr. Myounghoon Jeon

Committee Member: Dr. Susan Amato-Henderson

Committee Member: Dr. Pasi Lautala

Department Chair: Dr. Susan Amato-Henderson 


\section{TABLE OF CONTENTS}

Abstract.

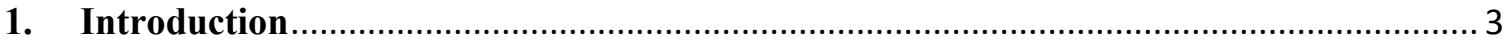

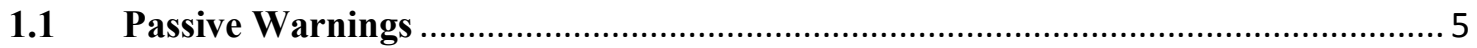

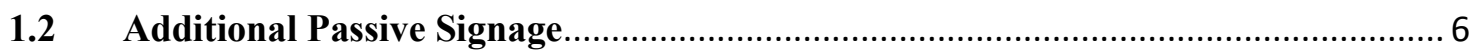

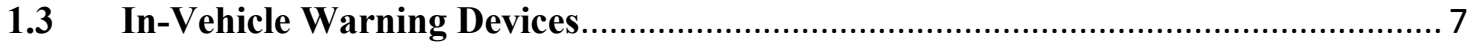

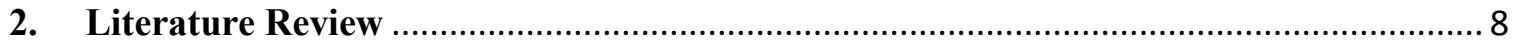

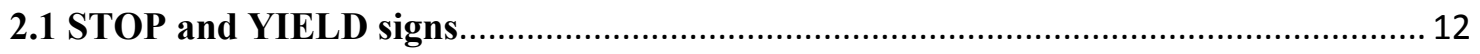

2.2 Warning Credibility (Reducing Warning Times and False Alarms) ........................... 14

2.3 Quiet Zones, Whistle Bans, and Wayside Horns........................................................ 17

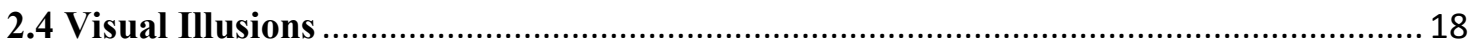

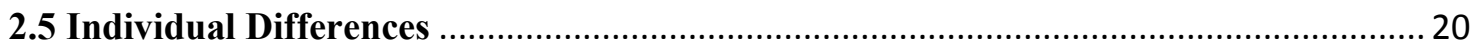

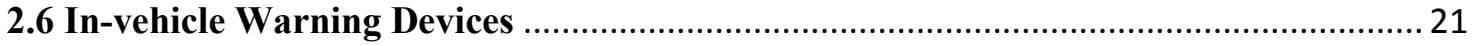

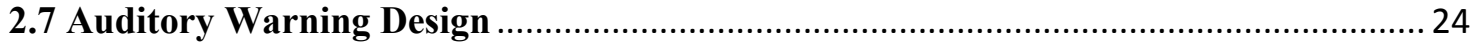

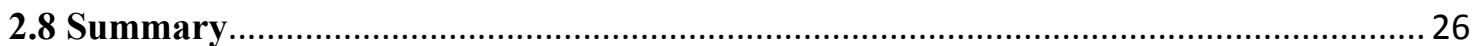

3. Study 1 - Subjective Evaluation of Potential Auditory Cues............................................. 28

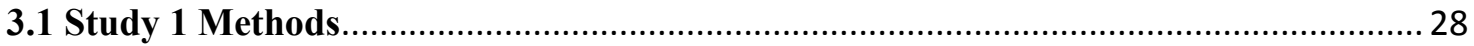

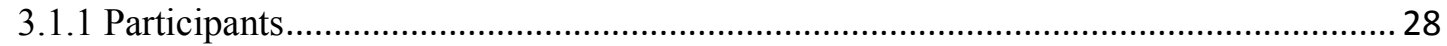

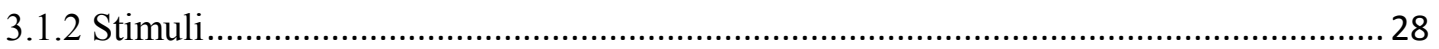

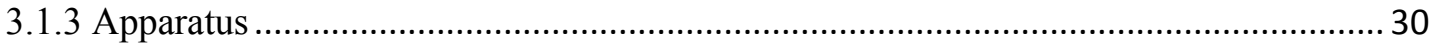

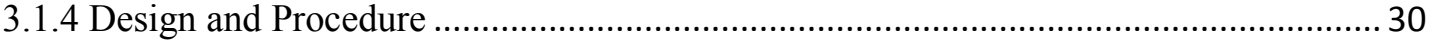

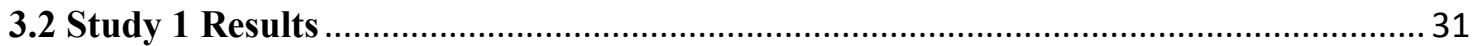

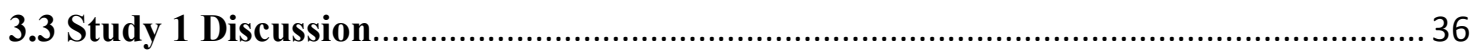

4. Study 2 - Compliance to RR In-Vehicle Auditory Warnings in a Driving Simulator ...... 37

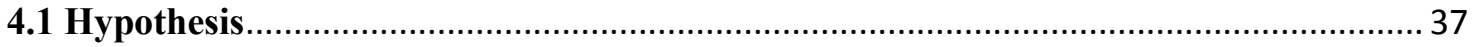

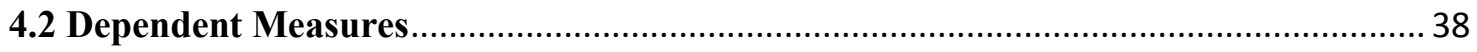

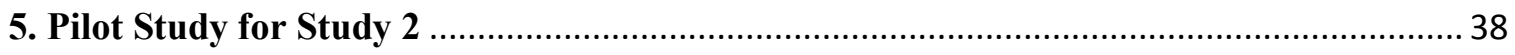

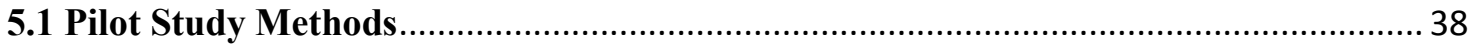

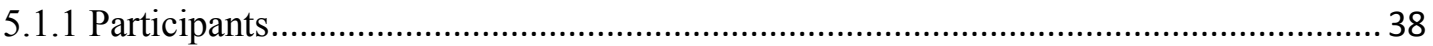

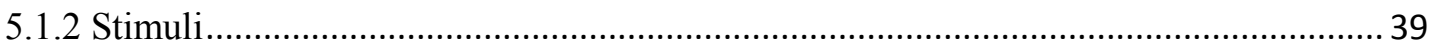

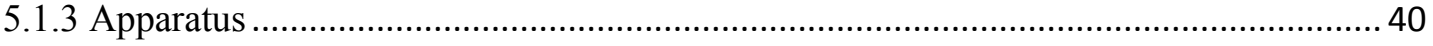


5.1.4 Design and Procedure

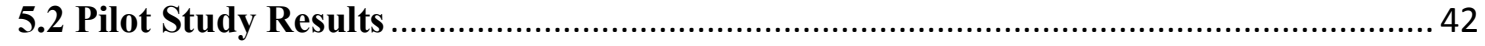

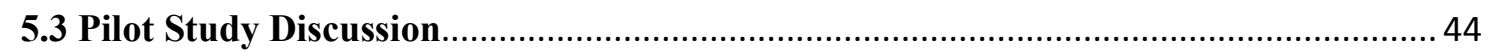

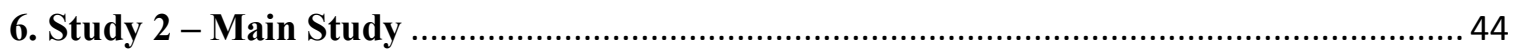

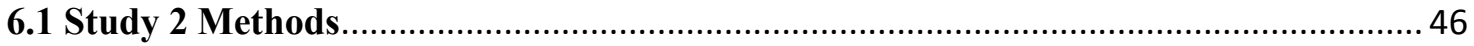

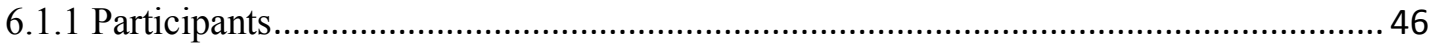

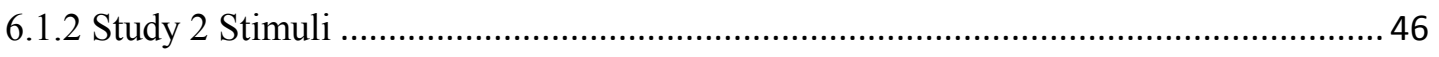

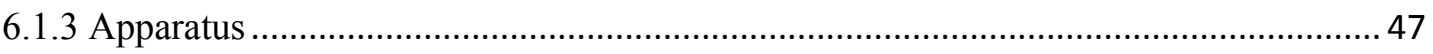

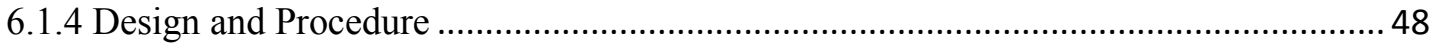

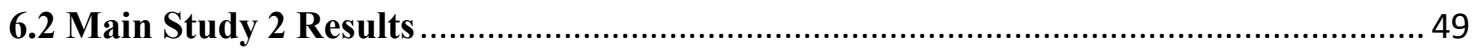

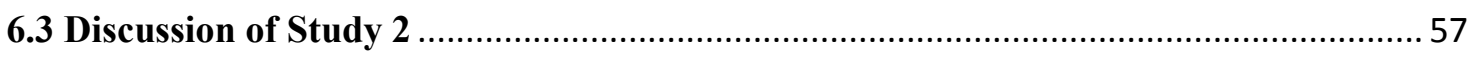

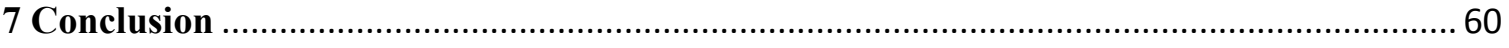

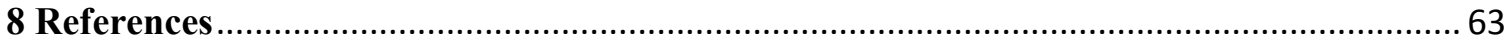




\begin{abstract}
Train-vehicle collisions at highway-rail grade crossings continue to be a major issue in the US and across the world. Installing additional hardware at individual crossings is expensive, time consuming, and potentially ineffective. To prevent recent trends in safety improvement from plateauing, experts are turning towards novel warning devices that can be applied to all crossings with minimal cost. In-vehicle auditory alerts (IVAAs) could potentially remedy many of the human factor issues related to crossing safety in a cost effective manner.

This thesis presents a series of experiments designing and testing an IVAA system for grade level railroad (RR) crossings. Study 1 collected subjective data on a pool of potential in-vehicle auditory alerts from 31 undergraduate participants. The type of IVAAs was varied along a number of dimensions (pitch, repetition, wave shape, wording, voice, etc.). Results from study 1 were used to design a prototype IVAA crossing notification system. A pilot study was conducted to calibrate the simulated driving scenario featuring multiple RR crossings and a compliance behavior coding procedure. Compliance behavior was operationalized as an amount of visual scanning and pedal depression.
\end{abstract}

Study 2 recruited 20 undergraduate participants to drive in a medium fidelity driving simulator featuring four types of RR crossings with and without IVAAs. Results suggest that IVAAs not only inform and remind drivers of how to comply at RR crossings, but also have a lasting effect on driver behavior after the IVAA is no longer presented. Compliance scores were highest among novel RR crossing visual warnings such as crossbucks featuring STOP or YIELD signs. Compliance was lowest for 
crossbucks alone and active gates in the off position. IVAAs had the largest impact on compliance scores at crossbucks and gates. The discussion includes implications for designing IVAA systems for RR crossings, and the potential implementation of prototype systems as a smartphone application. 


\section{Introduction}

A vehicle is struck by a train once every one-and-a-half to three hours in the United States, often with deadly results (oli.org, retrieved 10/21/14). Although less frequent than vehicle-vehicle collisions, a vehicle-train collision is twenty times more deadly, due to the 4000-to-1 train-to-vehicle mass ratio (Yan, Han, Richards, \& Millegan, 2010). According to the Federal Railroad Administration (FRA), in 2014 there were 2,286 highway-rail incidents leading to 852 injuries and 269 fatalities in the United States (safetydata.fra.dot.gov, retrieved 10/21/14). This marked the first time in the past decade that incident rates increased from the previous year. These figures are just a fraction of what they were only a few decades ago (Figure 1). Grade crossing collisions rates dropped by $75 \%$, and fatalities dropped by $70 \%$ between the years of 1975 and 2001 (Mok \& Savage, 2005). The main factors contributing to this decline are a $35 \%$ decrease in the number of public RR crossings, a 147\% increase in the number of crossings guarded by active warnings, the installation of advanced warning signage, and public awareness campaigns such as Operation Life Saver. Although the United States has made great strides in improving safety at RR crossings since the 1970s, vehicle-train accidents remain a large scale concern for the rail industry, costing millions of dollars every year and taking or destroying countless numbers of lives (Yeh \& Multer, 2008). 


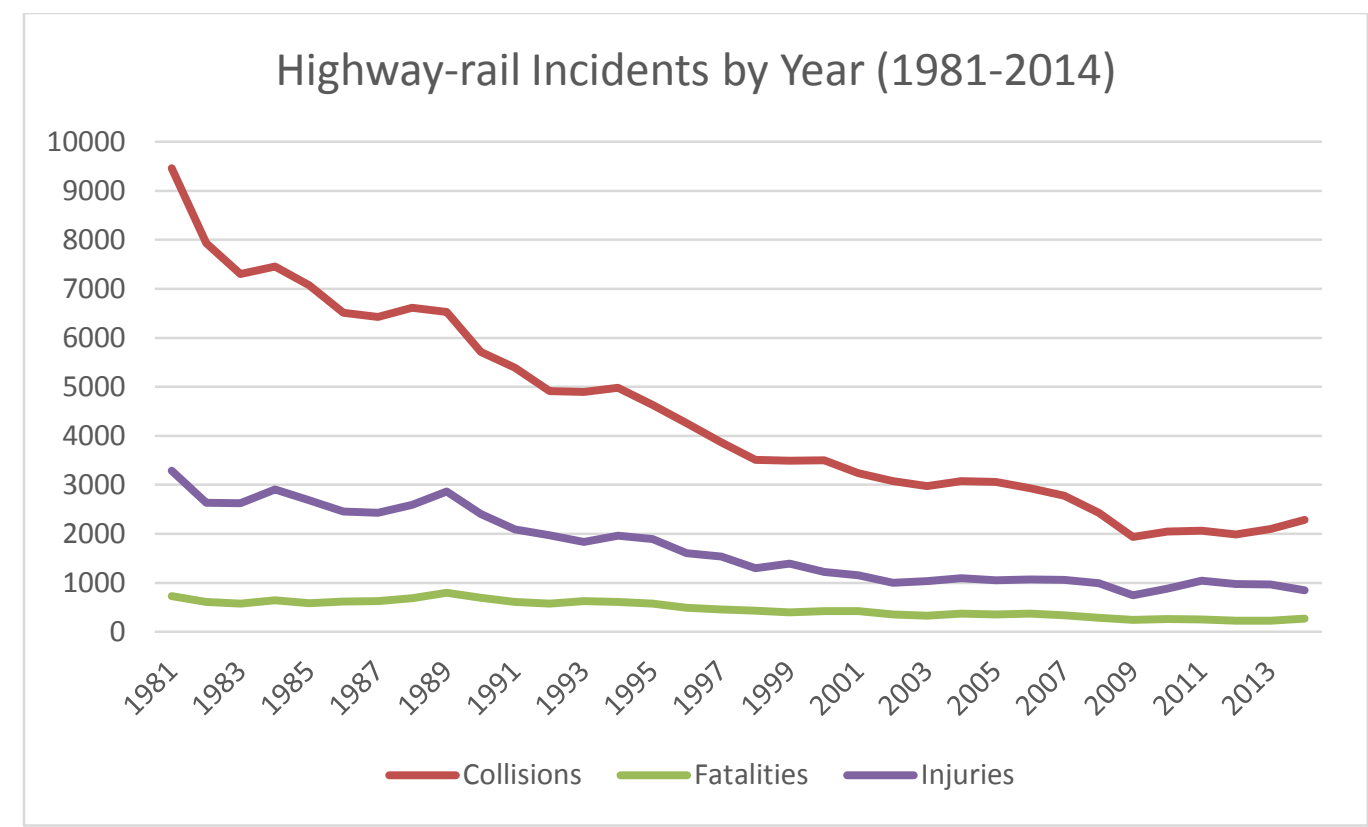

Figure 1. Collisions, fatalities, and injury rates from 1981- 2014 (safetydata.fra.dot.gov, retrieved 10/21/14).

In an ideal world, all RR crossings would be completely separated from highway traffic. Unfortunately, grade-separated crossings cost anywhere from $\$ 1.5$ to $\$ 3.5$ million per crossing (Soot, Metaxatos, \& Sen, 2004). The extreme cost for separating highways and rail lines leaves more than 212,000 highway-rail intersections nationwide with the potential for vehicle-train collisions. Due to financial limitations, the FRA, state, and local governments allocate their resources to identify and protect intersections deemed most dangerous. Formulas for predicting the likelihood of collisions at intersections include factors, such as volume and speed of vehicle and rail traffic, intersection visibility, and history of accidents (Yeh \& Multer, 2008). A cost-benefit ratio is calculated to determine if the predicted reduction in collisions justifies the cost of upgrading the warning system. Recent reports suggest that most of the crossings that justify the cost of an active warning system installation have already been upgraded and 
that resources would be better spent on novel intervention methods such as in-vehicle alerts (McCollister \& Pflaum, 2007).

\subsection{Passive Warnings}

Passive signs are the first line of defense for trains at RR crossings. The crossbuck, an X-shaped warning sign at RR crossings, is at the lowest end of the warning device scale, and is regarded as the bare minimum requirement for alerting drivers of an approaching crossing. Crossbucks are by far the cheapest warning technology to install and maintain and have been shown to improve safety compared to no warning at all. Pavement markings and other additional pre-warning signs are also considered to be passive warnings which direct the driver's attention to the crossing. Passive signage provides no information relating to the presence or absence of a train and is the least visually salient of all warning types. For a complete list of the cost and relative effectiveness of the different type of RR warnings, refer to Table 1.

Table 1. Countermeasure type, effectiveness, and cost (Ogden, 2007)

\begin{tabular}{|l|l|l|}
\hline \multicolumn{2}{|l|}{ Countermeasure } & \multicolumn{2}{c|}{ Cost of Installation } \\
\hline STOP/YIELD sign & Unknown & $\$ 1,200$ to $\$ 2,000$ \\
\hline Flashing Lights & $\begin{array}{l}83 \% \text { reduction in deaths over } \\
\text { crossbucks }\end{array}$ & $\$ 20,000$ to $\$ 30,000$ \\
\hline Gates w/ Lights & $\begin{array}{l}\sim 100 \% \text { reduction in deaths over } \\
\text { crossbucks }\end{array}$ & $\$ 150,000$ to $\$ 250,000$ \\
\hline $\begin{array}{l}\text { Flexible traffic } \\
\text { channelization devices }\end{array}$ & $80 \%$ increase in safety & $\$ 15,000$ \\
\hline $\begin{array}{l}\text { In-vehicle Crossing } \\
\text { Safety Advisory } \\
\text { Warning Systems }\end{array}$ & Unknown & $\begin{array}{l}\$ 5,000 \text { to } \$ 10,000 \text { per } \\
\text { crossing plus } \$ 0 \text { to } \$ 250 \\
\text { for a receiver }\end{array}$ \\
\hline
\end{tabular}




\subsection{Additional Passive Signage}

The Intermodal Surface Transportation Efficiency Act (ISTEA) of 1991 required states to allow for STOP and YIELD signs to be added to passive crossings (FHA, 2009). In the early 1990s, the rail safety literature argued that adding a STOP sign improved safety at passive RR crossings and reduced the number of collisions compared to crossbucks alone. As a result of this research, states started installing STOP signs at any and all passive crossings as a cheap way to increase saliency and compliance at crossings (Russel \& Burnham, 1999). It was later argued that compliance rates for STOP signs at RR crossings are among the lowest of all warning types, especially at crossings with a relatively low hazard rating (high visibility and low volume of vehicle or train traffic). Installing unnecessary STOP signs can train drivers to ignore STOP signs regardless of the context, and thus, lower the credibility of STOP signs everywhere. For these reasons, the FHWA now requires an engineering study to be conducted beforehand to determine if a particular crossing warrants a STOP sign installation (Russel \& Burnham, 1999).

Due to the inconsistent literature on the effectiveness of STOP signs at RR crossings, in 2006 the Federal Highway Administration recommended that YIELD and crossbuck signs be the standard passive warning (Ogden, 2007). In 2009 a new piece of legislation was passed in the United States that will require all passive crossings to be equipped with a crossbuck accompanied by either a STOP or YIELD sign by 2019 . Because less literature is available on using YIELD signs at RR crossings, it is important to determine their effects on driver behavior and compliance before indiscriminately installing them at all passive crossings (Yeh \& Multer, 2008). 


\subsection{In-Vehicle Warning Devices}

Now that GPS, smartphone, and in-vehicle display technology have become less expensive and more popular, the infrastructure is in place to make in-vehicle auditory alerts (IVAAs) a reality. As of 2015, the FRA and Google have entered into a partnership to include the location of all RR crossings in Google Maps services. Currently, no formal plans have been made public to introduce in-vehicle warnings for RR crossings. A type of warning system that could be easily implemented with the current technology is to provide in-vehicle notifications to alert the driver to the presence of RR crossings. More advanced systems could deliver information about the presence of trains once they can be accurately and reliably located by GPS. These warnings could also include dynamic messages about particular crossings as a driver approaches them, such as multiple trains approaching, reduced visibility, or known faulty equipment.

In-vehicle alerts for RR crossings could dramatically improve safety at all passive crossings, any crossing that resides inside a whistle ban area or quiet zone, and also for any crossing with multiple tracks. Novel warning systems will only be beneficial if drivers perceive them to be credible and trustworthy (Yeh \& Multer, 2008). To ensure this will be the case for in-vehicle alerts, end users must be considered and involved in the design and testing process. This thesis aims to provide evidence for the benefit of invehicle auditory alerts (IVAAs) for RR crossings. Implementing IVAAs can be an economically sound strategy for increasing the saliency as well as the credibility of warning systems at $R R$ crossings nationwide. 


\section{Literature Review}

Active warnings do not guarantee safety at RR crossings. Flashing lights, ringing bells, and active gates are intended to inform drivers of approaching trains and the need to stop before the crossing and wait for the train to pass. Unfortunately, many drivers use active warnings as a cue to hurry through the crossing to avoid the delay caused by the passing train (Yeh \& Multer, 2008). The most likely scenario of a collision at an active crossing involves a driver noticing the active warning (e.g., lights flashing, gates dropping) and then choosing to ignore it. If there is not enough evidence (mostly visual) that a collision will occur, the driver may pass through the crossing even if lights are activated, bells are ringing, and the gate is dropped. The driver also may ignore the warning and pass through the crossing if he or she sees other drivers ignoring the warning and passing through safely. Long warning times also encourage non-compliant behaviors such as gate-running. Multiple small vehicles can pass through unscathed after the onset of a warning before the train arrives at the crossing. Each time this occurs without a collision, a driver's risky behavior is reinforced. The problem with this scenario is when drivers become overconfident in their ability to estimate the time to arrival (TTA) of the train. There are a number of visual illusions that cause drivers to over-estimate the TTA of trains, leading them to falsely believe that they will have enough time to cross safely. The most effective countermeasure to prevent this type of risky behavior is to provide a physical barrier between the driver and the intersection, removing the possibility of gaterunning. Gate arms that extend across multiple lanes and median lane dividers make it inconvenient (or ideally impossible) for drivers to circumvent the gate. 
The battle for safety at passive crossings can be more complex. Passive warnings such as crossbucks are cheaper to install and require less maintenance than their active counterparts. They are always installed at all highway-rail intersections, and are the only required signage for crossings with low vehicle and train traffic. Of course, the downside of passive warnings is that they provide no information on the presence or absence of a train. TTA judgment errors may cause incidents at passive crossings, but there are many more "failure to notice crossing/train" errors than at active crossings. Intervention methods such as increasing the saliency of the crossing and providing train-present information are expected to be as effective at passive crossings as active warnings with no physical barrier (flashing lights and bells).

The majority of fatalities and collisions in the past five years occurred at crossings protected by active gates and lights as shown in Figure 2 (safetydata.fra.dot.gov, retrieved $10 / 21 / 14)$. This is somewhat expected given that gates are allocated to the most hazardous highway-rail intersections.

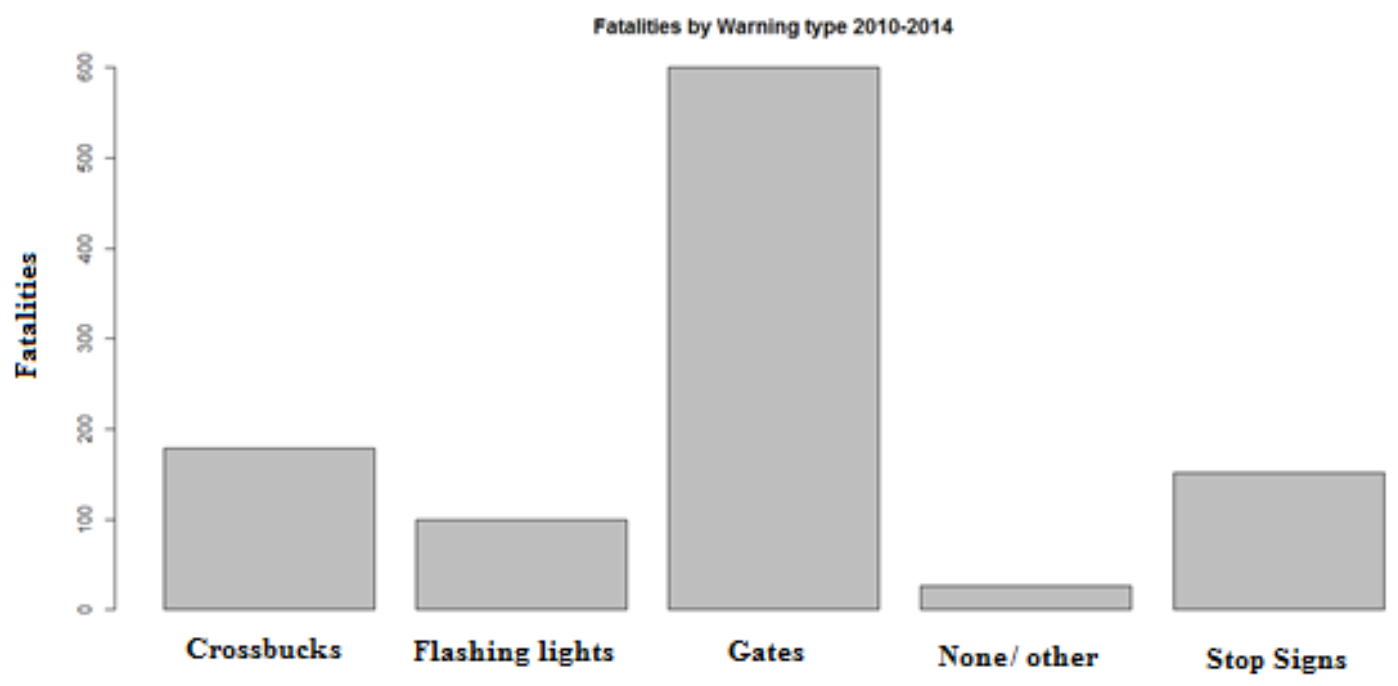

Figure 2. Fatalities by warning type from 2010-2014 (safetydata.fra.dot.gov, retrieved $10 / 21 / 14)$. 
Gates are 80 to $90 \%$ more effective at reducing incident rates than crossbucks alone (oli.org, retrieved 10/21/14), yet we still see a large majority of accidents at crossings already equipped with the best type of warning. A better representative statistic to determine the efficacy of different warning types would need to account for the volume of vehicle and rail traffic (exposure level). For instance, Raub (2006) analyzed collision data from 1994-2003 for seven Midwestern states with high levels of rail activity. He analyzed the annual rate of collisions as a function of warning device, but factored in the level of exposure by expressing the statistic in "collisions per 100 million crossing vehicles." The results for the four most popular types of warnings are shown in Table 2 .

Table 2. Collisions per 100 million crossing vehicles by warning type (Raub, 2006).

\begin{tabular}{|c|c|}
\hline \multicolumn{1}{|c|}{$\begin{array}{c}\text { Device } \\
\text { Type }\end{array}$} & $\begin{array}{c}\text { Collisions } \\
\text { per 100 MCV }\end{array}$ \\
\hline STOP signs & 4.76 \\
\hline Crossbucks & 1.87 \\
\hline Lights & 2.75 \\
\hline Gates & 0.71 \\
\hline
\end{tabular}

From this analysis, STOP signs appear to be the worst type of RR warning (Raub, 2006). This may be a remnant artifact of the policy to place STOP signs at any crossings, regardless of hazard level. If the hazard level is too low, compliance rates drop below that of crossbucks alone. On the other hand, if the hazard level of a crossing is high enough, active warnings would be far more effective than STOP signs since they provide train present or absent information (Yeh \& Multer, 2008). 
Noncompliant behavior such as gate-running is the biggest cause of accidents at crossings protected by active gates, while failure to detect the crossing or train, or at least, a poor TTA judgment, is the largest cause of accidents at crossings protected by passive warning signs (Yeh \& Multer, 2008). Because the nature of the breakdown in safety is due to different issues depending on the type of crossing, multiple countermeasures to increase safety must be developed to specifically target each issue independently and to promote respect for RR warnings in general.

Incident records in the FRA database often lack detail, making interpretation of the data difficult. Each record includes quantitative and qualitative data that describe each incident, including a narrative section. Unfortunately, most of the narratives fail to describe the behavior of the driver and sometimes even conflict with other information provided in the quantitative descriptions (Yeh \& Multer, 2008). In addition to the lack of consistency and lack of accurate or descriptive narratives, records of the signage type at crossings are often out of date. This suggests that some crossings are upgraded from passive to active warnings without the FRA crossing inventory being updated.

From the information available, Figure 3 suggests that the majority of collisions occur as the driver is attempting to cross in front of the train. A report from 2007 indicated that more than $20 \%$ of the collisions in California between 2000 and 2004 occurred when the driver ran into the side of the train (Cooper \& Ragland, 2007). The same study reported that more than $75 \%$ of all collisions in California occurred at crossings equipped with gates. The same does not hold true for all states. In Illinois, another state with a large volume of train activity, only $22 \%$ of train-vehicle collisions occur at active crossings (http://www.icc.illinois.gov/ilol/, retrieved 8/13/2015). 


\section{Action of vehicle at time of incident (2010-2014)}

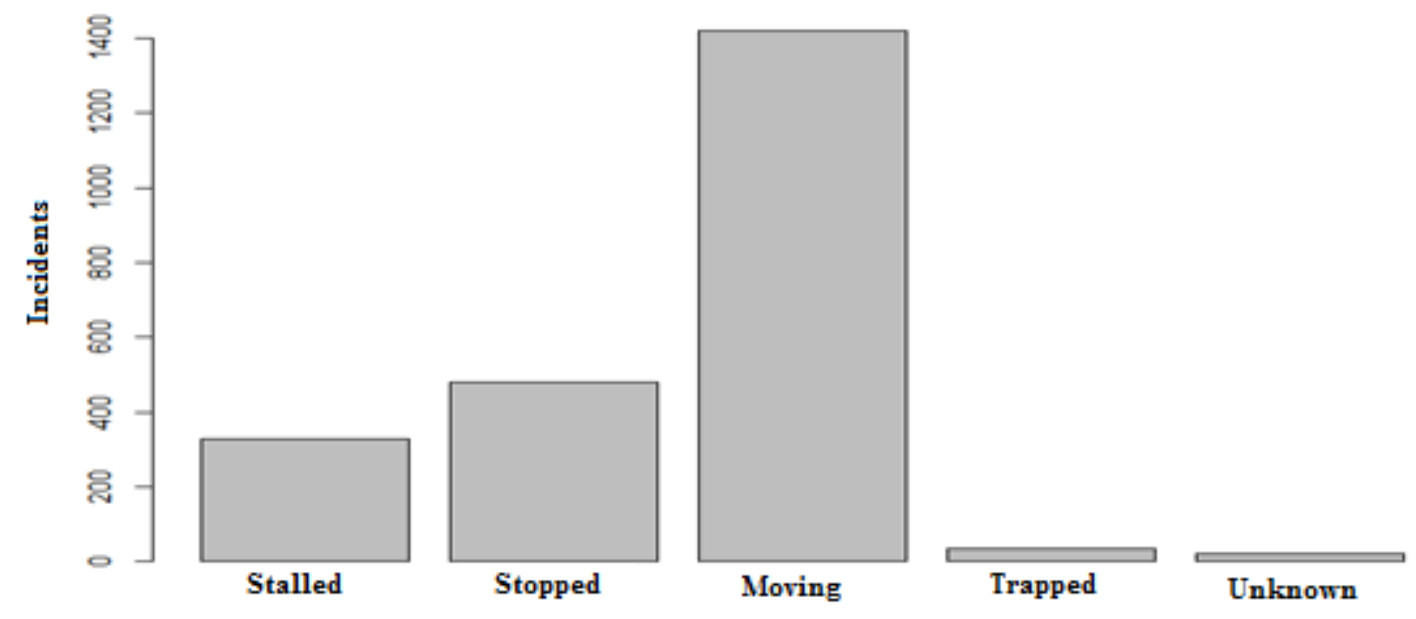

Figure 3. Action of the driver at the time of collision from 2010-2014 (safetydata.fra.dot.gov, retrieved 10/21/14).

\subsection{STOP and YIELD signs}

The idea to add a STOP sign at RR crossings was introduced because many drivers do not know exactly what a crossbuck sign is supposed to indicate or the appropriate action required by the driver. In a survey sponsored by the Texas Department of Transportation, $66 \%$ of respondents had incorrect assumptions on the correct driver behavior in response to a crossbuck (Fambro, Shull, Noyce, \& Rahman, 1998). STOP signs are more easily identified and understood than crossbucks. Additionally, installing a STOP sign is by far the cheapest safety upgrade; the sign's efficacy is, however, still under debate. An analysis of the collision rates over a 26-year period indicated that adding a STOP sign to certain intersections reduced the frequency of crashes compared to intersections guarded by only a crossbuck over the same period (Yan, Han, Richards, \& Millegan, 2010). Ngamdung and DaSilva (2012) reported that drivers were extremely likely to visually scan in at least one direction following the installation of a STOP sign (90\%); however, the authors conceded that this could have been due to the novelty of the 
warning and would likely decrease over time. Driving simulator studies also indicate that participants are more likely to slow down and visually scan for trains in the presence of a STOP sign compared to a crossbuck-only condition (Lenné, Rudin-Brown, Navarro, Edquist, Trotter, \& Tomasevic, 2011).

There are a few noteworthy historical analysis of incident records that indicated no benefit, or even noted an increase in incident rates, after STOP signs were installed (Raub, 2006). This study also suggested that STOP signs have the highest incident rates, controlling for level of exposure. One field study suggested that there was no reliable increase in drivers visually scanning for a train or coming to a complete stop at intersections with a STOP sign, compared to observed intersections equipped with only a crossbuck (Ward \& Wilde, 1995). Lerner, Ratte, and Walker (1990) noted that adding a STOP sign reduced approach speed and increased looking behavior, but drivers had much lower compliance rates than when STOP signs were used at roadway intersections. The use of STOP signs at RR crossings (and drivers' habits of ignoring them) could also have the unintended consequence of training drivers to develop a habit of ignoring ALL STOP signs anywhere. Another concern is the high rate of non-compliance at STOP sign grade crossings, including drivers coming to a rolling stop or stopping on the tracks. This type of behavior actually increases the time the vehicle is in the intersection, exposed to the train (Fambro, Schull, Noyce, \& Rahman, 1997).

Burnham (1994) reported that people treat STOP signs differently at RR crossings than at roadway intersections. Only $18 \%$ of drivers complied in a small-scale field observational study; $32 \%$ did not stop at all and 50\% slowed to a roll or stopped on the crossing before proceeding through. 
It is not that the case that STOP signs always lead to higher rates of incidents. In fact, an accident analysis over 26 years of train-vehicle crash history identified a clear benefit of adding STOP signs under certain crossing conditions (Yan et al., 2010). Especially for crossings with limited visibility and higher volume of trains, STOP signs reduce crash risk over crossbucks alone. However, when STOP signs are indiscriminately installed at all passive crossings regardless of hazard level, compliance rates decrease and the risk of incident grows.

Due to the inconsistent literature on the effectiveness of adding STOP signs at RR crossings, in 2006 the Federal Highway Administration recommended that YIELD plus crossbuck signs be the standard recommended passive warning. However, YIELD signs are not without their own controversy. Russel and Kent (1993) argued that YIELD signs slowed people down on approach only in the short term and had little effect on driver behavior in the long term. Additionally, they reported that looking behavior actually decreased in both the short and long term, contrary to what one would expect from a YIELD sign.

\subsection{Warning Credibility (Reducing Warning Times and False Alarms)}

The Manual of Uniform Traffic Control Devices (MUTCD; FHA, 2009) requires a minimum of 20 seconds of warning time (the time between signal activation and the arrival of the train at the crossing) for any train traveling $20 \mathrm{mph}$ or faster, which is most trains (FHA, 2009). The 20 second minimum is based on the time a large 18 -wheeler would need to pass through a multiple-track crossing from a stopped position. However, as train speed varies, these warning times can become unreliable. For instance, multiple observational field studies have indicated that the average warning time for a driver at 
any given active crossing is around 55 seconds, ranging from 20 seconds to almost two full minutes (Richards \& Heathington, 1990; Coleman \& Venkataraman, 2001). Longer warning times are associated with an increase in observed violations in both natural and experimentally controlled observations. After a field observation period, Bowman (1989) reported that the most violations occurred when the warning time was greater than 50 seconds at gated crossings and 35 seconds at flashing light crossings. Coleman and Venktarman (2001) went as far as to say that the number of violations increased about $15 \%$ for every 10 -second delay beyond the 20 -second minimum. Richards and Heathington (1990) provide specific recommendations of 20 to 25 seconds for crossing with lights, and 25 to 30 seconds for crossings protected by gates and lights for single track crossings. They also recommended that the gate delay time (the time between the activation of the lights and the start of the gate descent) should be approximately three to four seconds. These ranges were developed after testing for driver expectations for warning times with both types of active crossings. Through lab simulations and interviews, they determined that their participants expected a train to arrive within 15 seconds of the onset of warning light activation and within 30 seconds of a light plus gate activation (Richards \& Heathington, 1990). This finding highlights the tradeoff between the FRA's struggle to enforce redundant safety measures and the public's tolerance for delays.

Many active crossings are equipped with fixed-distance based triggers that are activated when a train approaches a crossing. Since these trigger circuits only detect the presence of the train and not its velocity, the TTA at the crossing is calculated from the train's maximum expected velocity. Unfortunately, train approach speeds can vary wildly 
below the maximum expected velocity (trains may even be stopped upstream of the crossing), causing drastically inflated and inconsistent warning times. Although slightly more expensive, constant warning time triggering systems are becoming more standard and have been shown to drastically reduce (and more importantly, standardize) warning times at active crossings (FRA, 2009). There is a general consensus in the literature that the reduction and standardization of warning times are associated with higher rates of driver compliance (Richards, Heathington, \& Fambro, 1990).

Unfortunately, these benefits are not always immediately observable, since the public is generally not aware of the existence or location of crossings with constant warning time systems (Halkias \& Blanchard, 1989). The logic remains that raising the credibility of one crossing's warning system will foster more respect towards all crossings in general, but it takes much longer for people to regain trust in an automated system they once trusted than it does for them to lose trust in the system in the first place (Bowman, 1989). A few misses or false alarms from an automated system results in a drastic decline in the user's perceived creditability of the system. This phenomenon is known as automation bias, which states that users are less likely to forgive automated decision aids for mistakes than they are for the mistakes of fellow human agents (Cummins, 2004).

Unreasonably long (and inconsistent) warnings are not the only influence on a driver's low level of perceived credibility of rail warnings. A driver's previous exposure to false alarms (when the active warning is triggered without the presence of a train) and the more dangerous "misses" (when a train is present but the warning is not triggered) certainly influences the perceived credibility of the system and thus, the driver's behavior 
at a crossing. Research in other domains with some form of automated alerts suggests that false alarms motivate users to ignore or respond slower to the situation (Cvach, 2012). While false alarms at rail crossings result in a decrease in compliant behavior, missed signals can actually lead to more cautious driving behavior (Yeh \& Multer, 2008). To the best of my knowledge, no one is arguing that intentionally missing signals would result in an overall increase in cautious driving behaviors.

\subsection{Quiet Zones, Whistle Bans, and Wayside Horns}

Auditory warnings from a train horn are only effective if the driver is able to detect and recognize the sound above ambient noise levels, and knows the appropriate response action (Skeiber, Mason, \& Potter, 1978). Environmental factors such as terrain at the crossing can negatively influence the detectability of sound. Sometimes, due to the environment, the train horn was only exceeding the ambient noise level when the train was 100 feet from the crossing. Skeiber et al.'s report showed that sound levels around a 200 feet radius from the crossing were unacceptable for an outdoor residential noise environment, and negatively impacted the quality of life for those who live and work in that area (Rapoza, Raslear, \& Rickley, 1999). Especially for areas that contain churches or schools, the use of quiet zones in which a train is not allowed to use its horn as an auditory warning is a practice to help alleviate the noise pollution around crossings. However, there is considerable evidence suggesting that the restriction of the train horn as an auditory warning consequently increases the hazard level of a crossing, resulting in more incidents. Crossings with whistle bans had an average of $84 \%$ more collisions than similar crossings without whistle bans (Yeh \& Multer, 2008). The use of wayside horns located at the crossing can remedy many of these issues. They have been shown to reduce 
the ambient noise level around the track while concentrating the auditory warning in the direction of the intended traffic. Having the sound source closer to the crossing has been shown to decrease drivers' perceived distance of the train, resulting in more compliant and safer driving behavior. We can further expand on this user-targeted warning system through the use of in-vehicle alerts. If the proximity of the sound source to the listener promotes a more conservatory biased distance estimate, we can expect IVAAs to improve decision making. There is a very detailed procedure for implementing a quiet zone. It involves replacing the train horn with more than one other safety device. Most situations require installation of active crossings with gates. Usually one or more crossings in the quiet zone are permanently closed to improve safety

\subsection{Visual Illusions}

Analysis of RR crossing violations indicate that active warnings are used by drivers merely as an indicator that a train is present, not as an indicator of TTA as they are intended (most likely due to inconsistency and inflated warning times). Some drivers rely on their own ability to assess the distance and speed of the train using available visual cues, such as visual angle (apparent size) and retinal displacement (apparent movement) of the train. Unfortunately, humans are surprisingly inaccurate and overconfident at estimating a train's TTA (Leibowitz, 1985).

Several studies have shown that driver estimates of speed and distance of approaching vehicles were largely inaccurate due to a number of visual illusions and cognitive biases. Barton, Cohn, and Kenyon (2006) tested the Leibowitz hypothesis, which states that larger objects are perceived to be moving more slowly than smaller objects with a similar velocity. Participants in this study underestimated the velocity of 
larger objects (spheres) in a driving simulator. Another simulator study conducted by the National Transportation Safety Board (NTSB, 1998) concluded that drivers are unable to effectively estimate the speed of an oncoming train due to the hyperbolic growth in size or visual angle of the train on approach. Since the rate of change of visual angle is hyperbolic (as opposed to linear), participants underestimated the speed when the train was farther away since the train size increased very slowly. It is not until a train is less than 500 feet away (when a train is traveling at $40 \mathrm{mph}$ ) before the rate of change in visual angle is obvious enough to make an appropriate estimation of speed.

A low rate of retinal image displacement is also a cause of underestimating the speed of a train as a driver approaches a crossing. Since both the vehicle and train are approaching a common point (the crossing) at perpendicular angles, the image of the train during approach stays at a constant position on the driver's retina, suggesting that the train is actually stopped or moving very slowly.

Sometimes, human factors engineers will try to augment the perceptual cues drivers use for these distance and speed estimation tasks, such as the arrangement of ditch lights in a triangle in front of the train's engine or wayside horns. These engineering solutions can enhance the distance and speed cues drivers use to make time to arrival judgments. For instance, if the IVAAs could manipulate the driver's perceived distance and direction of the train by presenting train sounds (e.g., horn, bells, track noise) from particular speakers in the vehicle. Augmenting the cues drivers use for distance/speed estimations has been shown to reduce risky behaviors and assist in decision making, but some experts warn that distorting the cues people use for these types of calculations may have unintended or opposite effects or consequences. 


\subsection{Individual Differences}

Rail accident demographics are similar to those of highway accidents. Younger and older (as opposed to middle-aged) people and males are most at risk. Younger drivers have less experience, less skill, and are more susceptible to distraction and indecision, while older drivers may have less than perfect vision or hearing and much slower reaction time. Driver personality or driving style also influences the variance of behavior seen at crossings. Some people are prone to risk taking and actually enjoy racing the train to the crossing. Surveys of risk seeking behavior have been correlated with the likelihood of drivers to exhibit noncompliant behavior and with drivers' increased confidence in their ability to cross safely in front of a train. External pressures, such as traffic from the rear or blindly following the lead vehicle can lead to driver error. Upstream traffic signals that operate without any awareness of the nearby RR crossing can also influence how a driver behaves at a crossing. Internal pressures, such as running late or simply not wanting to get stuck behind a long train, also have an effect.

Fambro, Schull, Noyce, and Rahman (1997) conducted a survey to gauge driver knowledge of rail warning signage. Their survey indicated that $30 \%$ of the respondents did not know where advanced warnings and crossbucks were located in relation to the railroad track. Another 50\% did not know that advanced warning signs were used at both active and passive crossings. Another 34\% did not know that the crossbuck was used at both active and passive crossings. Risk seeking behavior is also a contributing factor to unsafe behavior at RR crossings. Some drivers are more willing to accept, or even seek, risky situations. A few respondents even reported that they enjoy the thrill of racing a train to the crossing. 
Expectancy plays a major role in decision making. Perceived credibility of a warning device, expected warning time, and perceived likelihood of a train (developed from past experiences) is a major factor in a driver's decision to comply or not. Drivers familiar with the crossing are more likely to exhibit non-compliant behaviors (Abraham, Datta, \& Datta, 1998). Every time a driver experiences a crossing with no train, their expectations for a train are lowered, making them more susceptible to riskier behavior. Every time they manage to safely travel through a RR crossing without checking for a train their behavior is reinforced. False alarms and unnecessarily long warning times will decrease drivers' perceived credibility of the warnings, making them more likely to ignore the warnings in the future. The longer (and more often) people get stuck waiting for a long train to pass, the more inclined they will be to try to avoid that delay in the future, resulting in more risky "try to beat the train" behaviors. Safe approach behavior (slowing down to visually scan for a train) actually increases the chance of having to stop and wait for a train to pass. Overall, train present experiences at crossing tend to be few and far between, which leads drivers to not expect trains. It is when these expectations are violated that cause drivers to shift from highly accurate automatized behavior to often inaccurate and highly variable behavior (Yeh \& Multer, 2008).

\subsection{In-vehicle Warning Devices}

A long term vision for Intelligent Transportation Systems (ITS) is the development of intelligent grade crossings in which rail infrastructure (with data on the location, direction, and speed of trains) communicates with ITS service providers (with data on the location, direction, and speed of vehicles). Rail operation centers could notify drivers through ITS services if a train is approaching the crossing. Inversely, ITS service 
providers could relay relevant vehicle traffic information to rail operation centers such as a stalled vehicle on the crossing or a malfunctioning gate or lights (Weiland \& Woll, 2002).

One of the proposed uses of connected technology includes the use of in-vehicle warning displays. These types of systems will be particularly useful at passive crossings with low saliency. Since GPS and other communication devices have become ubiquitous in vehicles and smartphones, there is already a low cost opportunity to deliver warnings to drivers. This type of warning system would add a low cost supplement to the existing system, providing additional safety to connected drivers, as long as grade-crossings are accurately depicted in the highway maps. The audio modality would be the preferred method of warning delivery, due to the highly visual nature of the driving task. The warning signal could be specifically targeted toward the intended recipients, bypassing the auditory restrictions enforced at quiet zones. Dynamic messages could also be displayed to alert the driver of specific circumstances. Having the GPS location of the train and the vehicle would also decrease the number of false and missed alarms, further fostering the respect and credibility of all warnings. The ability to integrate the auditory warning with a driver's current stereo system would allow the warning to cut into the invehicle noise environment, guaranteeing saliency much like personal navigation device directions. Overall, the impact of ITS communication is expected to reduce delays at crossings by the use of constant warning times, and reduce false alarms by preventing activation when trains are stopped upstream (Yeh \& Multer, 2008).

Because integrating rail communication with in-vehicle displays is so new, there is little evidence in the literature to fully identify all potential benefits and deficits for rail 
safety that in-vehicle displays have to offer. A few pilot programs have documented the benefits of in-vehicle displays for RR crossings. The states of Minnesota and Illinois examined the use of in-vehicle displays to alert drivers to the presence of grade crossings and approaching trains. These pilot programs indicated that user acceptance of the systems depends on not only the true reliability, but also on the perceived reliability of the system. Since these two prototype systems were only exploratory, their generalizability to all users and all types of crossings is extremely limited. Both were only deployed with commercial vehicles, such as school buses and only for crossings already equipped with active warnings (Benekohal \& Rawls, 2004a, Benekohal \& Rawls, 2004b). Almost half of the participants who experienced the in-vehicle warning systems considered them redundant, especially considering that school buses are required by law to come to a complete stop at all RR crossings regardless of whether or not a train is present. There was not enough data collected to determine any impact these systems may have on collision rates; it is promising, however, that no incidents were recorded for those vehicles during the prototype deployment. In addition, participants rated the audioonly version of the warning system as effective as standard analog auditory warnings such as train horns, bells, and whistles.

In a driving simulator study, Chugh and Caird (1999) varied the reliability of a heads up visual display warning system for grade level RR crossings. When reliability of the system was kept high (little to no false alarms or missed signals), compliance rates and trust in the system remained high. However, as the reliability of system decreased, drivers were more likely to exhibit riskier driving behaviors and ignore the alarm. This phenomenon is observed and explained in detail in other domains where alarm fatigue 
negatively impacts safety, such as in hospitals, cockpits, and control rooms (Cvach, 2012). Caird et al. (2002) suggested that the use of such systems may induce overreliance, which would result in fewer visual scanning behaviors for trains. Typically, there are always benefits and deficits of implementing this type of automation in complex tasks. However, as long as the reliability of such systems remain foolproof, and the system adequately implies to the driver that the train always has the right of way and it is the responsibility of the driver to avoid the train, improvements in safety will be expected.

Since the use of in-vehicle alerts at RR crossings has yet to be fully explored, a number of design elements remain to be tested and questions need to be answered before these systems are deployed to the general public. For instance, how many and what type of cues will best foster driver compliant behavior? Displaying an auditory warning at every stage of the crossing experience (e.g., crossing ahead, train ahead, train crossing, and train complete crossing) would result in alarm fatigue, encouraging drivers to disable or ignore the system. Displaying too much unnecessary information could further confuse drivers or distract them from their primary driving task. The system should display the bare minimum amount of information required to adequately assist a driver's decision making.

\subsection{Auditory Warning Design}

Having the alerts presented in the auditory modality is an obvious choice as they are complimentary to the mostly visual task of driving. Auditory cues allow the driver to keep their eyes on the road, and can be presented through either the vehicle's speaker system or the driver's mobile device's speakers. The three most common categories of 
auditory cues are Auditory Icons, Earcons, and verbal messages. Auditory Icons are a short clip of a natural sound that has an obvious relationship between the object or action it is referencing (e.g., a crumbling paper sound effect when deleting a file). Auditory Icons are easy to learn and remember because they take advantage of the listener's prior knowledge of the sound to object/action relationship (Dingler \& Walker, 2008). Auditory Icons are also responded to more quickly than other types of auditory cues due to a combination of their inherent meaning (derived from previous experience), and acoustic characteristics (Graham, 1999).

Earcons are short, synthetic, musical tones that have an abstract relationship to the object or action it is referencing (e.g., the beep from a vehicle's dashboard to indicate low fuel). Earcons can be more difficult to learn, remember, and discriminate, but can better represent abstract concepts that have no natural sound (e.g., "create new folder") (Dingler \& Walker, 2008). Earcons have more acoustic flexibility than Auditory Icons. Acoustic parameters such as frequency, rhythm, and onset/offset timing are more easily manipulated to imbed additional information, such as urgency (Graham, 1999).

Verbal messages can be either recorded human voices, or text-to-speech synthesis. Verbal messages have the benefit of being able to describe both concrete and abstract concepts. However, the presentation rate of and the reaction time to verbal messages is quite slower than the other auditory cue types, and verbal messages are easily masked by natural conversation (Sanders \& McCormick, 1987). Each cue type has certain advantages and disadvantages in different contexts. Therefore, it is critical to investigate each type in the intended environment and context to determine most appropriate auditory display design. 
Field observation studies allow researchers to observe actual driving behavior in relation to rail-grade intersections. However, they are extremely time-consuming, and researchers can only pay attention to a small number of intersections at a time. Driving simulators can be used to provide the controlled and increased exposure to oncoming trains that is missing in field studies (Triggs, 2002). However, this must be balanced against the risk of measuring non-representative behavior through exposure to a high number of low-frequency events within a short time period. Validation studies indicate that simulator measures are representative of on-road driving behavior, but this can be dependent on the participant's motivation and fidelity of the simulation (Godley, Triggs, \& Fildes, 2002).

\subsection{Summary}

To summarize the relevant issues relating to driver safety at RR crossings, the only way to completely remove the possibility of driver error is to close down the crossing, or separate the traffic with an overpass. Traffic control devices such as fourlane gates and median separators make it difficult, or at least inconvenient, for drivers to encroach on the crossing. Flashing lights are the next safest warning device, due to its ability to actively warn drivers of the presence of trains. The biggest weakness of active warnings is the inconsistent and often inflated warning times. Active warnings are also too expensive to install at all RR crossings nationwide. The biggest weakness of passive

warnings is that they provide no information about the presence of trains. Due to this, and the low rate of train present crossing experiences, drivers learn to ignore them.

In-vehicle auditory alerts (IVAAs) combine the strengths of active and passive crossings by being able to alert drivers to the presence of trains, and being relatively 
inexpensive. For a simple crossing notifications only type system, no additional hardware would need to be installed as long as the vehicle has some type of GPS tracking device in the vehicle. For the more advanced train warning system, additional lines of communication would need to be developed to connect the vehicle to rail infrastructures. Having the alerts presented in the auditory modality is an obvious choice as they are complimentary to the mostly visual task of driving. They allow the driver to keep their eyes on the road, and can be presented through either the vehicle's speaker system or the driver's mobile device's speakers. The locations of crossings are already integrated into popular navigation apps and devices, providing reference points for when and where to present the IVAAs. The ultimate goal is to have ITS service providers and rail infrastructure communicate to provide real-time dynamic alerts to drivers with consistent warning times.

The first step to achieving this goal is to develop and test a simple notification system to alert the driver to the presence of a crossing. This type of system could be deployed to the general public in the near future, without the need for train-vehicle communication. Crossing notifications could be presented to drivers regardless of the presence of trains. Both types of warning systems (crossings only, or train present alerts) will need to be properly developed and tested before widespread dissemination.

This thesis will attempt to evaluate the effectiveness of the simple type of IVAAs for RR crossings (crossing notifications only). The main issue to be addressed is whether or not IVAAs will increase safe and compliant approach behaviors, or will drivers learn to ignore them over time just as they do for passive crossings, or will they be perceived as 
not credible like active warnings. The development and testing of an IVAA crossing notification only system are presented in the following series of studies.

\section{Study 1 - Subjective Evaluation of Potential Auditory Cues}

My first study investigated the subjective perception of a wide variety of potential RR crossing auditory cues. This step was necessary to gauge not only people's preference for different types of auditory cues, but also their perceived level of urgency of the cues in order to properly map signal warning to its referent. The results of Study 1 were used to inform the design of the auditory display in subsequent experiments.

\subsection{Study 1 Methods}

\subsubsection{Participants}

Thirty-one $\left(M_{\text {age }}=20.1, S D_{\text {age }}=1.7 ; 17\right.$ male, 14 female $)$ psychology undergraduate participants completed the study in exchange for course credit. All participants were recruited through the Michigan Technological University SONA system. All participants had a valid driver's license and reported normal hearing ability. Informed consent was obtained at the beginning of each session, and each participant was debriefed before being released.

\subsubsection{Stimuli}

I created a pool of thirty potential auditory cues (five Auditory Icons, nine Earcons, and 16 verbal warnings) to alert drivers of an approaching crossings or trains. The five Auditory Icons included a steam whistle, the sound of a train rolling across train tracks, standard active rail crossing warning bells, a steam whistle, a train horn, and a combination horn plus tracks plus bells. Earcons varied by pitch, waveform, number of tones, and discrete or "siren-like" pitch oscillation; all of which are parameters related to 
the perceived urgency of Earcons (McGookin \& Brewster, 2004). All auditory stimuli are organized in Table 3.

Table 3. A list of all auditory stimuli, organized by group type.

\begin{tabular}{|l|l|l|}
\hline \multicolumn{1}{|c|}{ Earcons } & Warning (male, TTS) & Train tracks \\
\hline Beep low & Warning (male, human) & Warning bells \\
\hline Siren low & Warning (female, TTS) & Steam whistle \\
\hline Siren high & Warning (female, human) & Train horn \\
\hline Beeps fast simple low & Alert (male, TTS) & Track, horn, \& bells \\
\hline Beeps fast simple high & Alert (male, human) & \\
\hline Beeps x2 low & Alert (female, TTS) & \\
\hline Beeps x2 high & Alert (female, human) & \\
\hline Beeps x4 complex & Danger (male, TTS) & \\
\hline & Danger (male, human) & \\
\hline & Danger (female, TTS) & \\
\hline & Danger (female, human) & \\
\hline & Caution (male, TTS) & \\
\hline & Caution (male, human) & \\
\hline & Caution (female, TTS) & \\
\hline & Caution (female, human) & \\
\hline
\end{tabular}

Human Factors guidelines on the design of Earcons suggests that the pitch of an

Earcon should be between $125 \mathrm{~Hz}$ and $5000 \mathrm{~Hz}$ to ensure they are not easily masked and fall within the normal hearing range of most listeners (McGookin \& Brewster, 2004).

McGookin and Brewster also recommend that to ensure that the Earcons grab the attention of the listener, higher pitches and rapid onset and offset of amplitude should be utilized (2004). Eight of the nine Earcons were generated using the audio software Audacity. Two were continuous pure tones (1000 or $2000 \mathrm{~Hz}$ frequency). Tones pulsed at either a fast (400ms in length with $200 \mathrm{~ms}$ interval between tones) or slow (400 ms length with $800 \mathrm{~ms}$ interval) rate. Two "siren" tones were generated oscillating between 1000 
and 1500 , or 1500 and $2000 \mathrm{~Hz}$ at a pitch fluctuating rate of four cycles per second. No amplitude modification filter was used; tones are either completely on or off to maximize saliency. The final Earcon stimulus was generated using the software Max/MSP to closely resemble the familiar airplane intercom ding. Verbal warnings included the standardized precautionary words "Danger", "Warning”, "Caution", and "Alert" (Hellier, Edworthy, Weedon, Walters, \& Adams, 2002) spoken by either human (recorded voice) or Text-to-Speech (TTS) in both male and female gendered voices (4 words x 2 voice types $\mathrm{x} 2$ gender $=16$ total verbal warnings). All cues (Auditory Icons, Earcons, and verbal messages) were controlled for volume and length ( $\sim 70 \mathrm{~dB}, 1-2$ seconds).

\subsubsection{Apparatus}

SimuRide driving simulation software was used to prime participants for evaluating auditory cues in the context of driving. The scenario consisted of simple city driving with minimal traffic. No driving performance data was collected. Participants used a Logitech G27 USB Racing Wheel connected to a Dell Optiplex 780 PC with a 27 inch monitor to interact with the software. Auditory cues were presented and subjective ratings were collected by the Psychology Experimental Building Language (PEBL) software running a custom script to randomize the presentation order and record responses (Mueller \& Piper, 2014).

\subsubsection{Design and Procedure}

Participants were first instructed that they would be presented with a pool of auditory cues designed to warn drivers about oncoming railroad crossings or trains. Then the participants drove in a low fidelity driving simulator running SimuRide driving training software for five minutes. The driving session was used to prime the participants to have the in-vehicle noise environment fresh in their memory. Following the short 
driving simulation, the participants were presented with formal definitions of the seven dimensions used to rate the auditory stimuli. Each participant was presented with all 30 auditory cues and one practice cue (change dropping in a cup) over headphones at a volume between 60 and $70 \mathrm{~dB}$ 's using the PEBL software. Stimuli order was randomized for each participant. Participants could replay the cue as many times as they chose while they filled out the seven point Likert scales for each of the seven dimensions deemed relevant in previous auditory alert literature. These dimensions included: discriminability, meaning, urgency, natural response, annoyance, startle, and overall appropriateness (Baldwin \& Lewis, 2014).

\subsection{Study 1 Results}

First I analyzed the scores of each auditory group type. In general, participants preferred Earcons over Auditory Icons and verbal messages. They were rated to be significantly more annoying and startling (Figure 4), a quality necessary for a good auditory alert representing an urgent situation. However, as expected, Earcons in general scored lower on the meaning and discriminability dimensions compared to Auditory Icons and verbal messages. For the Overall score, Figure 5 shows that Earcons $(M=4.5$, $\mathrm{SD}=.77)$ were rated significantly higher than Auditory Icons $(\mathrm{M}=38, \mathrm{SD}=.92) ; \mathrm{p}<$ .0001 , as well as significantly higher than Verbal messages $(\mathrm{M}=3.9, \mathrm{SD}=.83) ; \mathrm{p}=.003$. There was no significant difference between Verbal messages and Auditory Icons. 

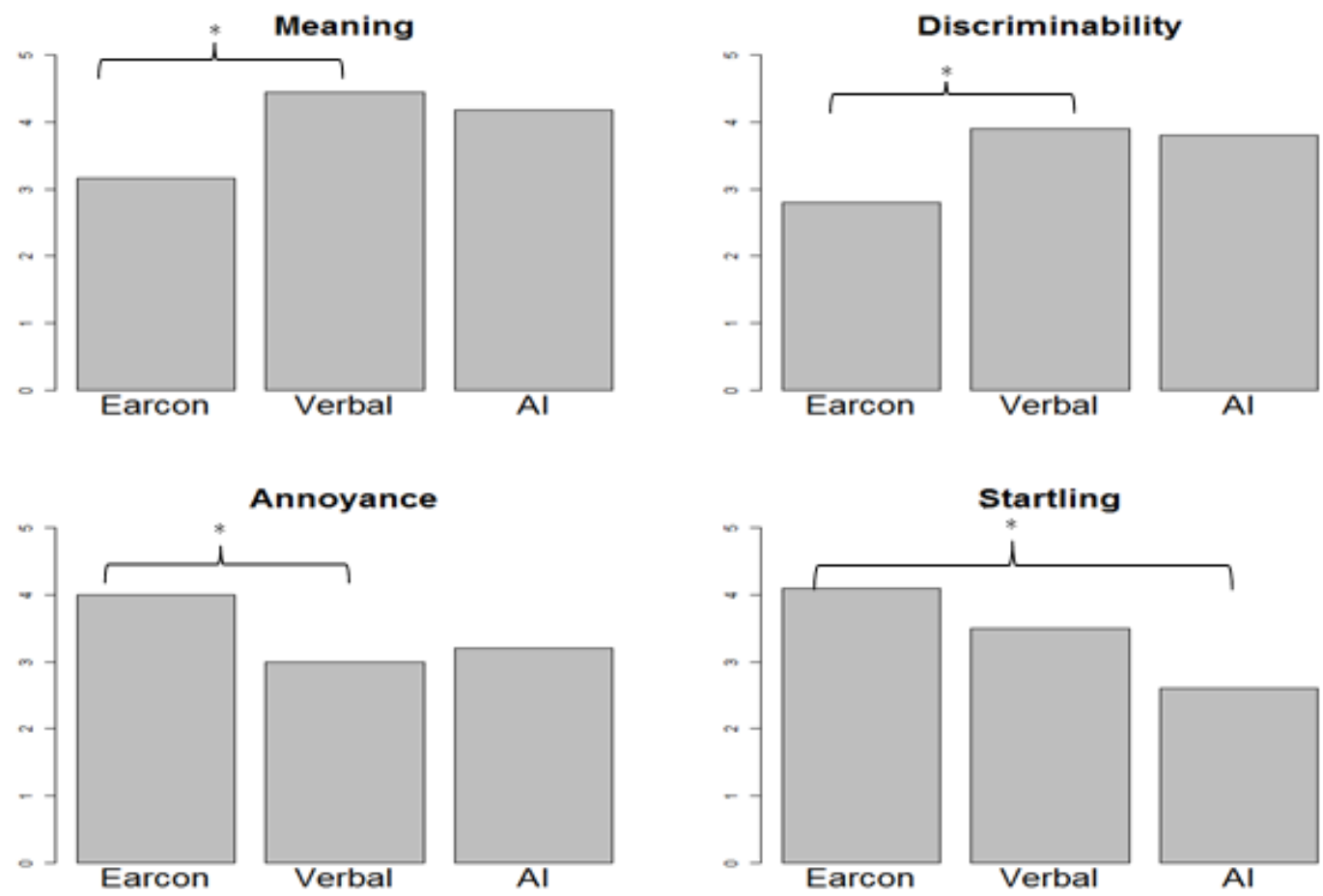

Figure 4. Meaning, discriminability, annoyance, and startle scores for each auditory cue type.

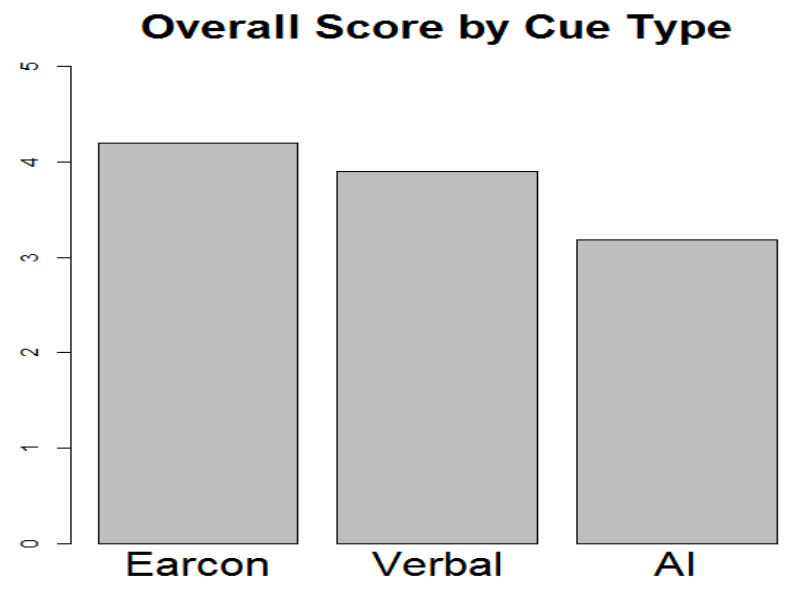

Figure 5. Overall score by cue type.

Next, I conducted a repeated measures ANOVA on the overall score for verbal warnings to investigate the effect of word (Danger, Alert, Caution, and Warning), Gender (male/female), and voice type (human/TTS) on overall rating. Results (Table 4) indicate a 
significant effect for Gender (Female: $M=3.98, S D=1.4$; Male: $M=3.68, S D=1.38 ; p$ $=.005$ ), and Voice type (Human: $M=4.03, S D=1.3$; TTS: $M=3.63, S D=1.44 ; p=$ $.001)$, and interactions for Word X Gender $(p=.008)$, Word X Voice type $(p=.014)$, and 3 way interaction for Word X Gender X Voice type $(p=.003$, Figure 6$)$. These two and three-way interactions are possibly a result of the particular text-to-speech engine that I used, in addition to the variance added by using two separate voice actors for the human verbal recordings. For instance, the TTS engine may have pronounced words differently across male and female personas, or the intensity of the recorded human voices may have not been constant across all words and voice actors. For the overall appropriateness dimension, participants vastly preferred female and human voices.

Table 4. ANOVA of Overall ranking by word, gender, and voice type.

\begin{tabular}{|c|c|c|c|c|c|}
\hline & Sum of Squares & df & Mean Square & $\mathrm{F}$ & $p$ \\
\hline \multicolumn{6}{|l|}{ Between Subjects } \\
\hline Residual & 335.375 & 26 & 12.899 & & \\
\hline \multicolumn{6}{|l|}{ Within Subjects } \\
\hline Word & 4.370 & 3 & 1.457 & 1.139 & 0.339 \\
\hline Residual & 99.755 & 78 & 1.279 & & \\
\hline Gender & 9.481 & 1 & 9.481 & 9.252 & 0.005 \\
\hline Residual & 26.644 & 26 & 1.025 & & \\
\hline Voice & 17.926 & 1 & 17.926 & 13.529 & 0.001 \\
\hline Residual & 34.449 & 26 & 1.325 & & \\
\hline Word:Gender & 13.111 & 3 & 4.370 & 4.195 & 0.008 \\
\hline Residual & 81.264 & 78 & 1.042 & & \\
\hline Word:Voice & 10.444 & 3 & 3.481 & 3.736 & 0.014 \\
\hline Residual & 72.681 & 78 & 0.932 & & \\
\hline Gender:Voice & 3.000 & 1 & 3.000 & 1.874 & 0.183 \\
\hline Residual & 41.625 & 26 & 1.601 & & \\
\hline Word:Gender:Voice & 15.296 & 3 & 5.099 & 5.061 & 0.003 \\
\hline Residual & 78.579 & 78 & 1.007 & & \\
\hline
\end{tabular}

Note. Type III Sum of Squares 

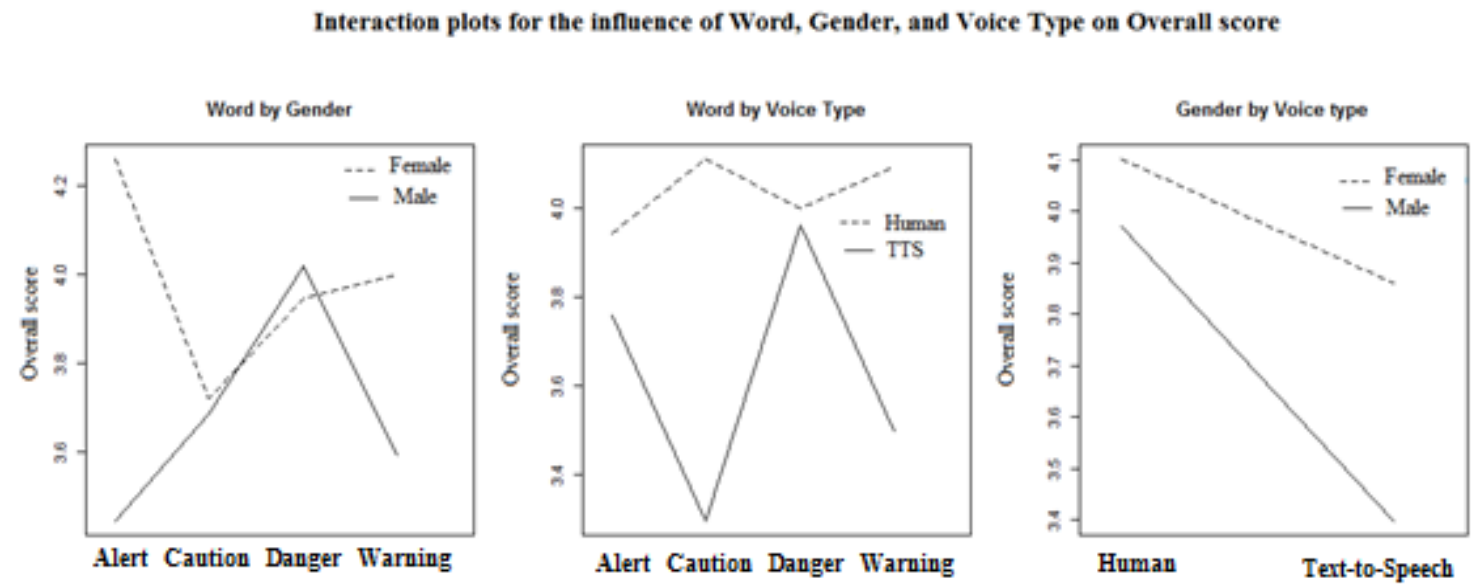

Figure 6. Interaction plots depicting the influence of Gender, Voice type, and Word on overall score.

The ranked order of urgency between the four words in Study 1 corroborates previous speech warning literature (Hellier et al., 2002). The verbal message "Danger" was rated as the most urgent, while "Caution" was rated as the least urgent of all verbal messages (Figure 7). I conducted six paired $\mathrm{T}$ tests to compare all combinations of words against each other. No significant differences were found, however the comparison between "Caution" $(M=3.7, S D=1.34)$ and "Danger" $(M=3.98, S D=1.47)$ was close to significance; $p=.052$. This suggests that "Danger" would be more appropriate to signal the arrival of a train (highest urgency situation), while "Caution" would be more appropriate to alert the driver of an approaching crossing (lowest urgency). 
Urgency Score by Word

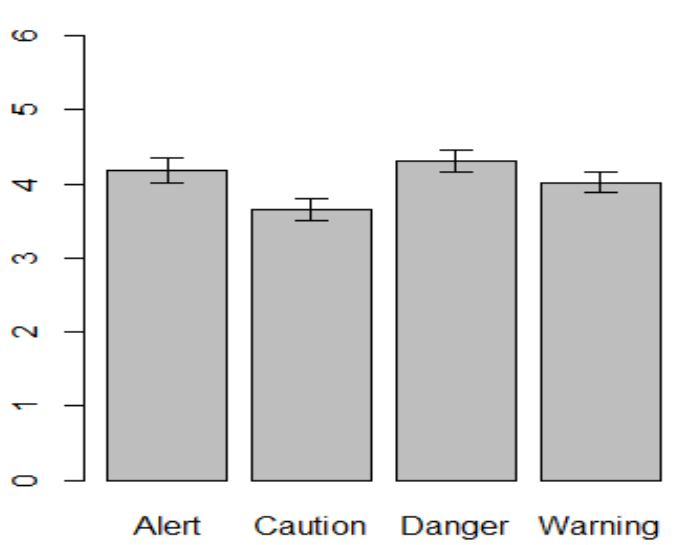

Meaning Score by Word

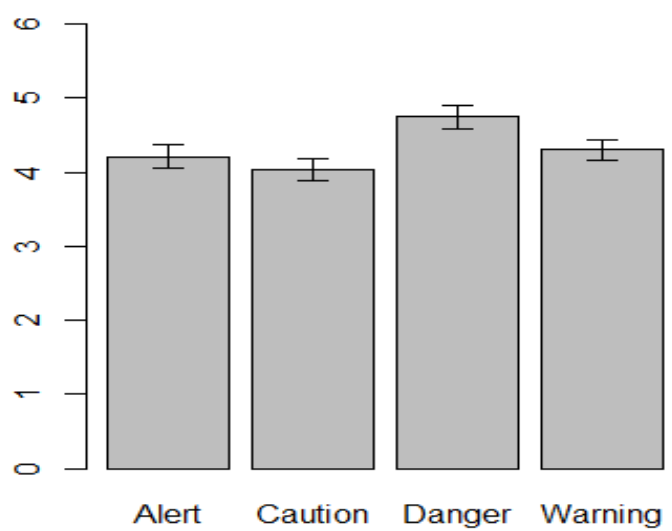

Figure 7. Urgency and meaning scores by word

Finally, I conducted a principal component analysis (PCA) on the seven dimensions of ratings to determine how many separate factors were captured in the survey. The PCA suggested the majority of the variance could be captured with only two factors. I then conducted a factor analysis with an Oblimin rotation with two main factors. The dimensions meaning, natural response, and urgency were combined to become a new factor I called "Utility", while the dimensions annoyance and startle effect were combined to become the new factor "Impulsivity". The dimensions, discriminability and overall appropriateness were not included as they failed to load on either of the two main components. Using these two factors I was able to compare the individual sounds against each other in a way that reflected the other features of each sound beyond the participant's overall appropriateness score. I used the loadings of each emerging factor for each auditory stimuli to collapse the five included dimensions down to two for visualization and clustering analysis, as seen in Figure 8. This technique helped me identify the acoustic features relevant for the perception of urgency in Earcons. For instance, wave shape seemed to be most influential feature. Earcons that used a smoother 
sine wave shape tended to be rated as less impulsive than more angular saw wave shapes. Multiple beeps were consistently rated as more impulsive than single beeps. Higher pitches also resulted in higher impulsivity ratings. This information was useful for mapping the acoustic urgency of Earcons to the level of hazard of its referent.

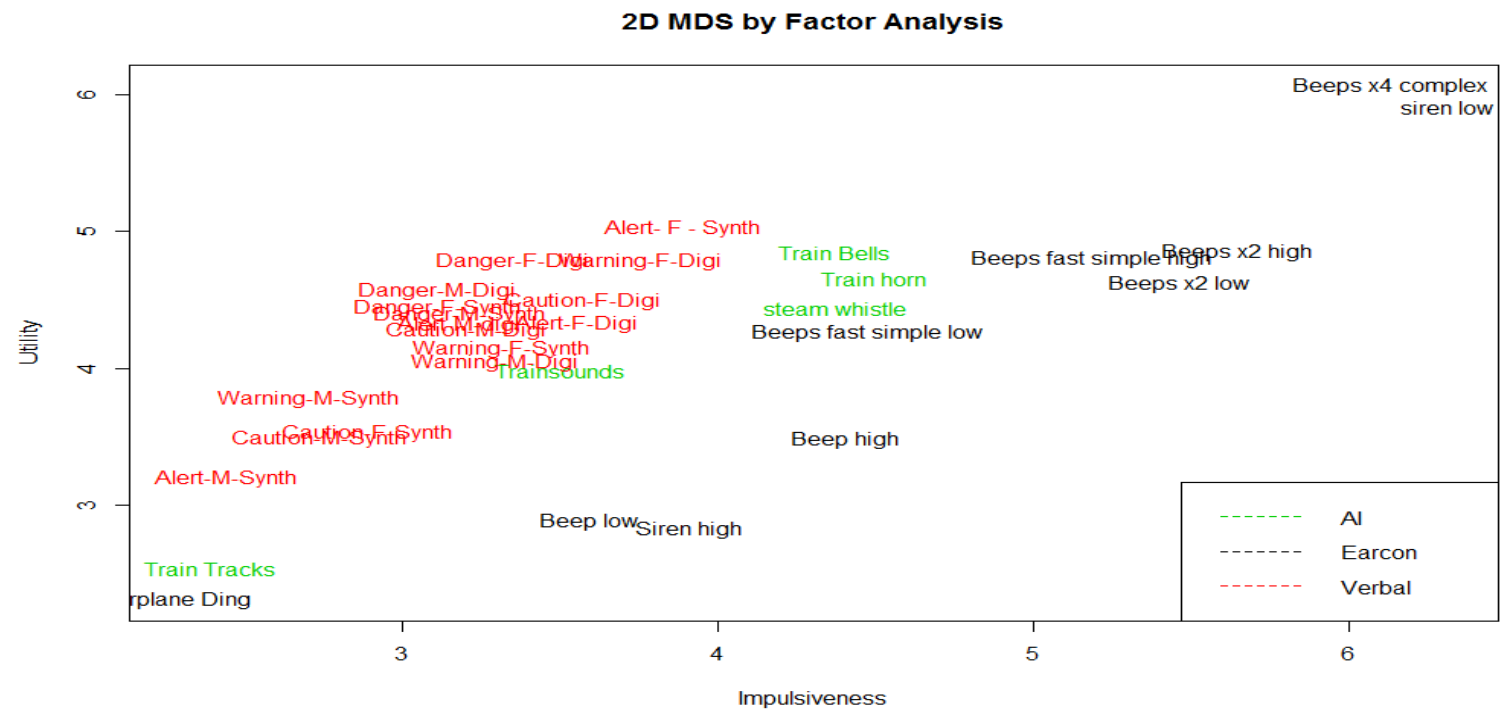

Figure 8. Two dimensional scaling based on principal component loadings.

\subsection{Study 1 Discussion}

There are two main phases of IVAA systems for RR crossings. The first phase consists of crossing notifications that direct the driver's attention to the presence of a RR crossing (like a passive sign). The second phase would warn drivers of an oncoming train (like an active warning). I would expect the second phase system (train warnings) to be more helpful for drivers, however this would require additional train-vehicle communication channels that currently do not exist. The phase one system (crossing notifications) could and should be developed and deployed first to ensure reliability and user acceptance of the novel warning system. Based on the results of the Study 1, I designed a crossing notification auditory warnings for RR crossings in the follow ways: 
Human voices were rated consistently higher in the overall appropriateness dimension, therefore I used a human voice instead of TTS generated voices. Since the urgency of a crossing situation is somewhat ambiguous when train presence is not known, it was important to design the warning with a neutral level of urgency. Earcons were rated as the most appropriate compared to Auditory Icons and verbal messages, but scored the lowest in the meaning dimension. Therefore, I used an Earcon with both high and low urgency elements (low urgency sine wave, played multiple times) as an initial beacon sound to grab the driver's attention. Following the beacon Earcon, I used a verbal message to both describe the situation and instruct the driver on how to appropriately respond ("crossing ahead, look left and right"). The auditory cue will be played approximately 5-15 seconds before the driver reaches the crossings, around the same time the driver passes through the pre-warning signs and pavement markings.

\section{Study 2 - Compliance to RR In-Vehicle Auditory Warnings in a Driving Simulator}

To test the efficacy of IVAAs for rail crossings, I developed and tested my prototype warning system. The overall system aims to address the main issues discussed in the literature review. The sound design of the system was informed by the results of Study 1 . The prototype system is comprised of crossing notifications only (phase one type), and could be implemented immediately given the current technology imbedded in smartphones and vehicle infotainment systems.

\subsection{Hypothesis}

Any novel auditory warning (in addition to standardized RR warnings) will improve rates of safe and compliant driving behavior in the simulated driving scenario. However, the effects may decrease over time as the novelty fades (operationalized by 
compliance habituation slopes). Increased behaviors include slower approach speeds, earlier release of accelerator pedal, higher rates of visual scanning, and higher compliance rates for STOP signs.

\subsection{Dependent Measures}

Compliance Behaviors

- Looking behavior (eye tracker/webcam) (before, during, after crossing). Did they look, in which direction, and for how long?

- Release of accelerator (coasting, first sign of "yielding to right-of-way")

- Brake pedal force (reducing speed on approach)

- Vehicle velocity (did they reduce their speed, or come to a complete stop)

\section{Pilot Study for Study 2}

The pilot study utilized a driving simulator to investigate how drivers behave in reaction to potential in-vehicle auditory alerts for approaching RR crossings. It served as an initial testbed for ensuring that the dependent measures were sensitive enough to adequately test my hypotheses. Only one potential "crossing notification only" system was tested and compared to a control group with no auditory alerts. Since accidents are such a rare occurrence, compliance is often used as a surrogate measure to predict the hazard level of crossings, or the potential for collisions.

\subsection{Pilot Study Methods}

\subsubsection{Participants}

Eight $\left(M_{\mathrm{age}}=26.2, S D_{\mathrm{age}}=2.1 ; 4\right.$ male, 4 female $)$ volunteer participants were recruited to take part in the pilot study. Participants were not compensated in any way. Two requested to stop the study early due to simulator sickness. All participants had a valid driver's license and reported normal hearing ability. 


\subsubsection{Stimuli}

\section{Scenario Design}

The simulated scenario was developed using the Tile Mosaic Tool (TMT) and Interactive Scenario Authoring Tool (ISAT), and presented to the participant using the National Advanced Driving Simulator (NADS) MiniSim version 2.2 software and hardware. The scenario consists of four RR crossings designed in accordance with the Manual on Uniform Traffic Control Devices (MUTCD, FHA 2009) developed by the FRA to reflect real world configurations of visual warnings. The first and fourth crossing consist of a crossbuck and YIELD sign on a relatively open rural type road, while the second and third crossings consist of a crossbuck and STOP sign positioned in a stretch of city road. STOP controlled crossings were positioned at an intersection which was visually occluded by buildings on either side, meeting the requirements for a STOP sign set forth by the MUTCD.

Each crossing was separated by approximately two to three minutes of driving, depending on the speed of the participant. All crossings included an advanced warning RR sign and pavement markings approximately 350 feet (or 5-10 seconds traveling at a speed of $50 \mathrm{mph}$ ) before the intersection. Light traffic is simulated in the opposing lane to improve the realism of the simulation, but not limit the participant in driving behaviors. Refer to Figure 9 for a simplified map of the created scenario. All participants experience one lap with no traffic to serve as both training and a simulator sickness check with no auditory alerts.

Following this portion, the participant drives four continuous laps around the scenario. Trains are only present on the $13^{\mathrm{h}}$ (YIELD) and $15^{\text {th }}$ (STOP) crossing. This allowed participants to grow accustomed to not expecting a train similar to natural 
driving conditions. I was careful to avoid including too many trains that would not reflect real world likelihoods of train presence. Having no trains for approximately twenty five minutes (or sixteen crossings) allows for enough train absent crossing exposures to bias the participant into similar train expectancy as observed in real world driving.

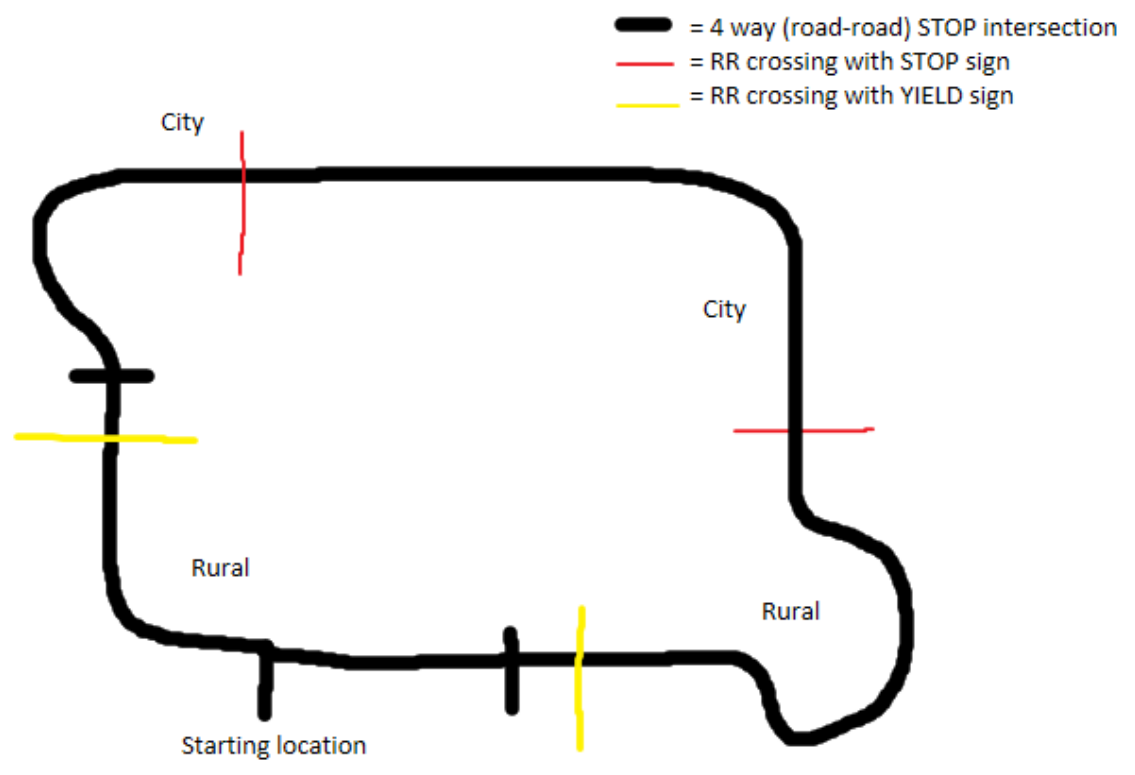

Figure 9. Pilot study scenario design.

For the experimental condition, auditory crossing notifications were presented through the simulator speakers at a volume ranging from $60-75 \mathrm{~dB}$ just before the vehicle passes the pre-warning signage for the crossing. The crossing notification consisted of a single Earcon beep, followed by the verbal message of "Rail crossing ahead, look left and right" that I had recorded in an isolated vocal booth.

\subsubsection{Apparatus}

The driving simulator consisted of a full sized cab with realistic steering wheels and pedals. Three large display screens are curved towards the participant to provide a near 180 degree viewing angle. The National Advanced Driving Simulator (NADS 
MiniSim) software and hardware was used. To measure visual scanning and compliance behavior, two webcams were placed on top the dashboard of the driving simulator. One was positioned to capture the participant's face while the other captured a small portion of simulator's visuals for synchronization. Both webcams streams were captured in a single window using the free Open Broadcast Software (OBS) on an auxiliary laptop. After collecting seven participant's data, I developed a coding scheme to operationalize visual scanning and compliance behaviors.

5.1.4 Design and Procedure

A between-subjects design was utilized to compare the control condition (no auditory alerts) and experimental condition (with auditory alerts). All participants drove one lap around the scenario to serve as a baseline and simulator sickness check. Following the warm up lap, the participant was randomly assigned to either the control or experimental condition, then drove four laps around the track while the simulator recorded all driving data and the webcams recorded the visual scanning behavior. Each lap contained four grade level RR crossings: two crossbuck with YIELD signs, and two crossbucks with STOP signs. A train was present on crossing thirteen and fifteen.

After seven participants had participated, I viewed the videos from the webcams and developed a coding scheme to operationalized visual scanning behavior (Table 5). A participant received one point for each direction they look (maximum two points), as long as it occurs after the advanced warning visual signs, and before the vehicle passes through the crossing. If the visual scan at a STOP protected crossings occurred too far away from the intersection to be useful (vision is occluded by the buildings), one point was subtracted from the total compliance score. If the visual scan is performed too close 
to the crossings with a YIELD sign for the participant to be able to come to a complete stop before the track in case a train is detected, one half of a point was deducted. If the crossing is protected by a STOP sign and the participant does not come to a complete stop (i.e., a rolling stop), one half of a point was deducted.

Table 5. Compliance coding scheme for the pilot study.

\begin{tabular}{|c|c|c|}
\hline \multicolumn{2}{|c|}{$\begin{array}{c}\text { Compliance } \\
\text { awarded } \\
\text { action }\end{array}$} & $\begin{array}{c}\text { Applicable } \\
\text { sign types }\end{array}$ \\
\hline $\begin{array}{c}\text { per direction } \\
(\max 2)\end{array}$ & $\begin{array}{c}\text { Visually scan for train } \\
\text { (at any time })\end{array}$ & All \\
\hline-1 & $\begin{array}{c}\text { Visually searching too } \\
\text { far from crossing }\end{array}$ & STOP \\
\hline-.5 & $\begin{array}{c}\text { Not coming to a complete } \\
\text { stop }\end{array}$ & STOP \\
\hline-.5 & $\begin{array}{c}\text { Visually searching too } \\
\text { close to crossing }\end{array}$ & YIELD \\
\hline
\end{tabular}

\subsection{Pilot Study Results}

As expected, visual scanning and compliance behavior is high in both control and experimental groups at the start of the scenario. Both conditions showed a decline in compliance score as exposure to crossings without a train increases. The current data suggests that, as hypothesized, the presentation of auditory crossing notifications improve compliance rates and promote slower habituation than the control group, as shown in Figures 10 and 11 . The $\mathrm{Y}$ axis denotes compliance score based on my coding scheme, and the $\mathrm{X}$ axis denotes individual crossings. The bars indicate group means for each individual crossing. Note how there is an increase in compliance for the seventh YIELD crossing and the eighth STOP crossing. Also, note how compliance in general is much lower for the YIELD crossings compared the STOP crossings. 


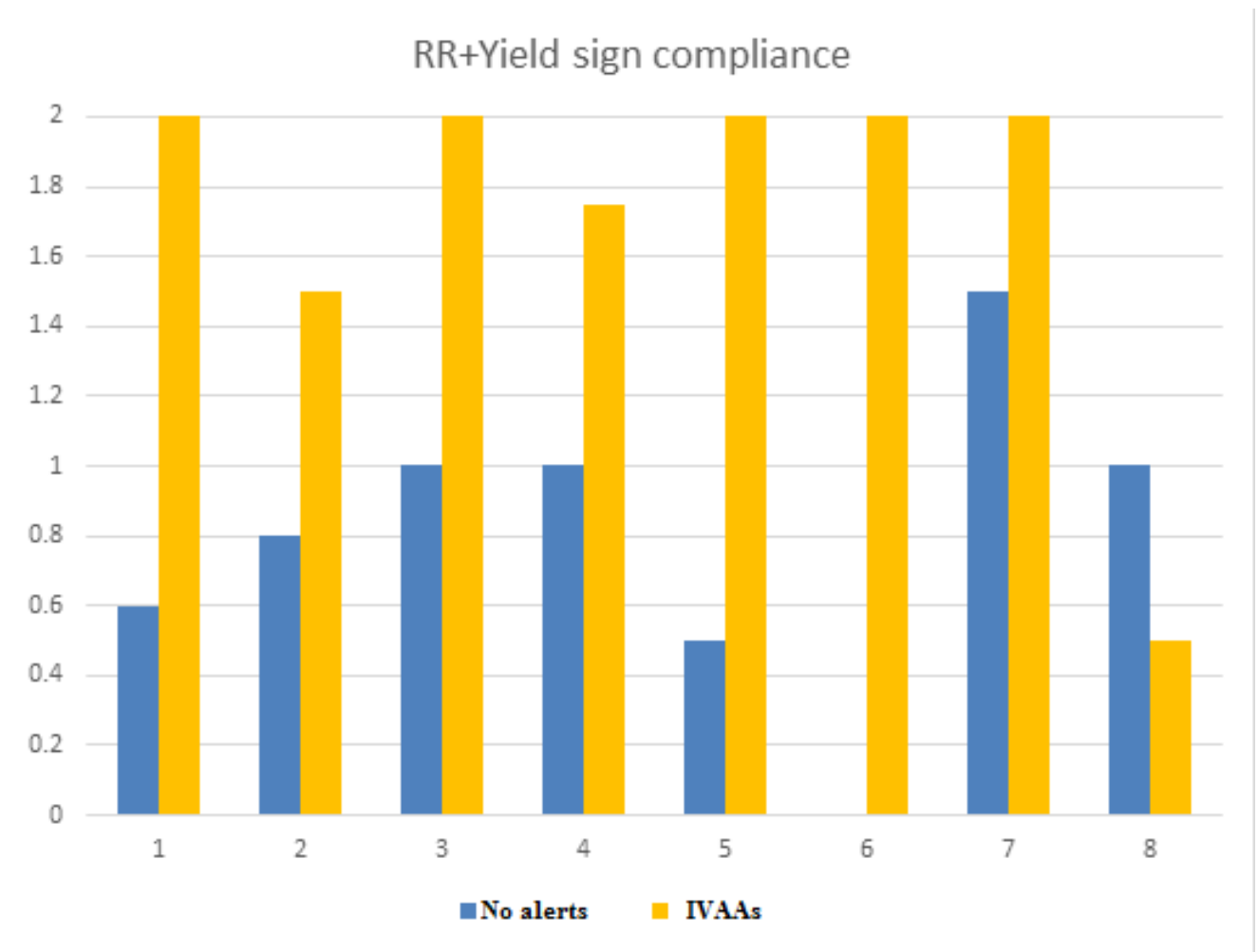

Figure 10. Compliance scores for RR + YIELD with and without auditory notifications over time.

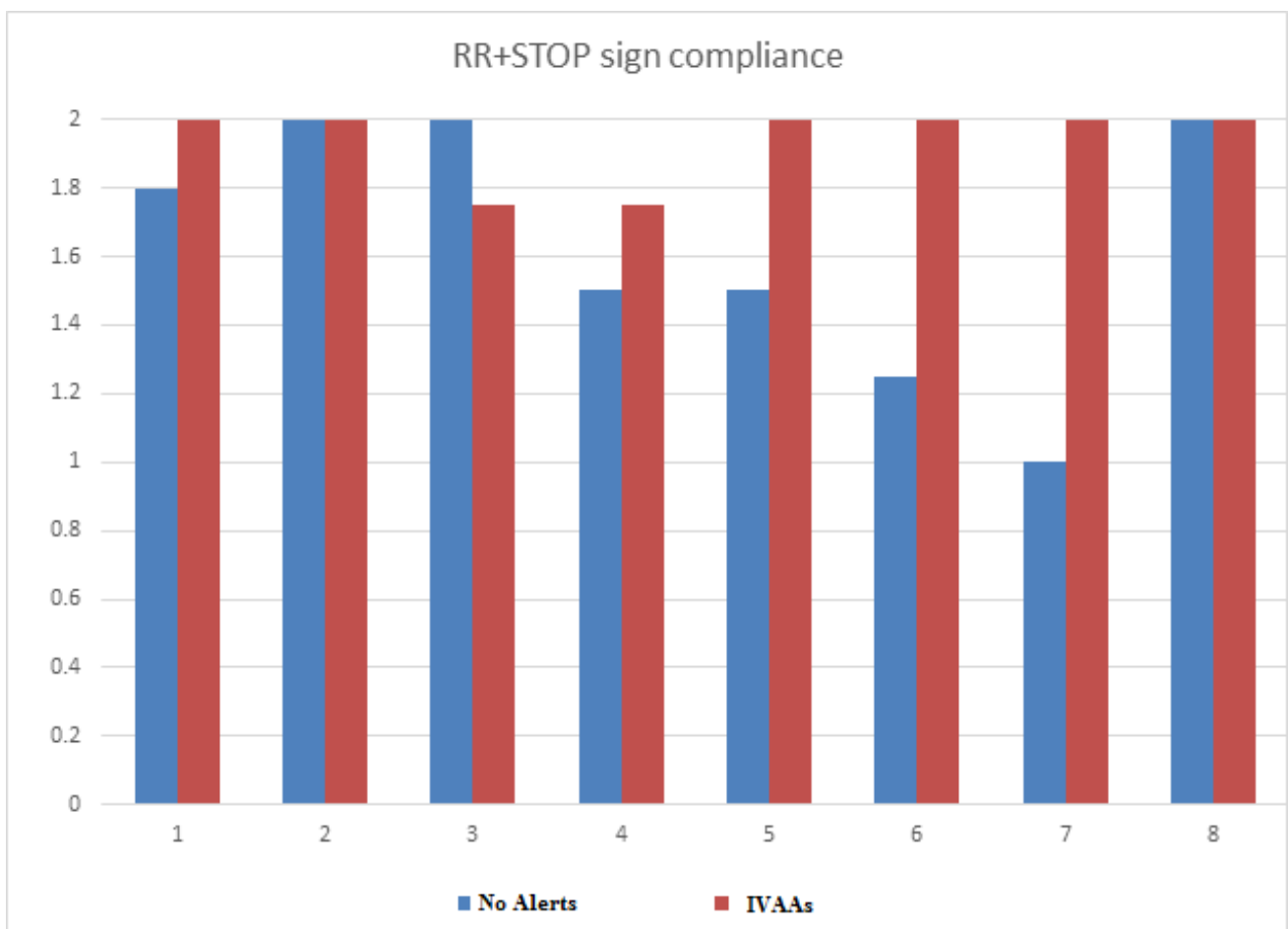

Figure 11. Compliance scores for RR + STOP with and without auditory notification over time. 


\subsection{Pilot Study Discussion}

The data collected is preliminary, but promising. The noticeable slope in compliance scores over time suggests that participants are habituating to the visual signage, or expecting a train less and less after every no train present crossing. What is interesting is the difference in slope between the control and experimental conditions. This suggests that the auditory cues serve as a reminder to comply better than visual signage only. An alternative explanation could be that the verbal messages also inform the driver how to comply. Note the sharp increase in compliance on the seventh YIELD crossings and the eighth STOP crossing. This is due to the presence of a train on the previous crossings. Once a train is presented, participants adjust their expectations of the relative likelihood of a train, and behave more conservatively. This provides evidence that the likelihood of compliance is directly related to the driver expectation of a train. The more train absent crossings the driver experiences, the less likely they will be to expect a train and less likely to comply with the signage at subsequent crossings. Once a train is introduced, participants adjust their expectancy, which leads to higher compliance rates.

\section{Study 2 - Main Study}

The main study was an extension of the pilot study. The system was designed to be fully implementable with the current state of vehicle-to-infrastructure communication (GPS only, identical to the notification system in study two). In this system, an auditory notification was presented to indicate to the driver of an approaching RR crossing, regardless of train absence or presence. Compliance scores for conditions with the IVAAs are compared against control conditions consisting of visual signs only and no 
IVAAs. The scenario includes four crossings with unique signage appropriate for the environment: a rural crossing with a crossbuck, a rural crossing with a crossbuck and YIELD sign, a city crossing with a crossbuck and STOP sign, and a city crossing with a full lights and gate combination. All crossings included advanced warning signage and pavement markings described by the MUTCD (FHA, 2009).

Compliance was measured in a similar manner as in the pilot study, with some modifications (Table 6). For each direction looked, one point of compliance was added to the participant's score for that crossing event (maximum of 2). If the driver released the accelerator pedal (coasting), another point was awarded. If the driver applied any force to the brake pedal (intentionally reducing vehicle speed), another point was awarded. If the driver failed to come to a complete stop at crossings that include a STOP sign, one point was subtracted from their total compliance score for that crossing. This balanced all compliance scores along the same four point scale, given that compliance at a STOP sign requires that the driver release the accelerator pedal, press on the brake pedal, and come to a complete stop. Therefore, compliance will be coded for each crossing event as a scale from 0-4 which includes both visual scanning and driving behavior. The scenario was designed so that visual searches that occurred before the pre-warning signs would be occluded by visual obstructions; if a train was present the participant would not be able to see it. Only behaviors that occur after the pre-warning signage but before the crossing contributed to the compliance scores for YIELD and crossbuck protected crossings. Search behaviors at the STOP and gate protected crossings were only awarded points if the search occurs at the intersection, otherwise the driver's vision down the track would have been occluded by buildings. 
Table 6. Modified compliance coding scheme for study 2.

\begin{tabular}{|c|c|c|}
\hline \multicolumn{1}{|c}{$\begin{array}{c}\text { Points } \\
\text { awarded }\end{array}$} & Compliance action & \multicolumn{1}{|c|}{$\begin{array}{c}\text { Applicable } \\
\text { sign types }\end{array}$} \\
\hline $\begin{array}{c}+\mathbf{1} \text { per direction } \\
(\max 2)\end{array}$ & $\begin{array}{c}\text { Visually scan for train } \\
\text { (at appropriate time) }\end{array}$ & All \\
\hline$+\mathbf{1}$ & $\begin{array}{c}\text { Release of accelerator pedal } \\
\text { (coasting) }\end{array}$ & All \\
\hline$+\mathbf{1}$ & $\begin{array}{c}\text { Applying any force to the brake pedal } \\
\text { (slowing down) }\end{array}$ & All \\
\hline$-\mathbf{1}$ & $\begin{array}{c}\text { Not coming to a } \\
\text { complete stop }\end{array}$ & STOP \\
\hline
\end{tabular}

\subsection{Study 2 Methods}

\subsubsection{Participants}

Twenty additional participants $\left(M_{a g e}=20.2, S D_{\text {age }}=.52,16\right.$ males, 4 females $)$ were recruited from the Michigan Technological University SONA system. One hour participation was exchanged for two credit points in an undergraduate psychology course. All participants had a valid US driver's license and over three years driving experience.

\subsubsection{Study 2 Stimuli}

The scenario of the main study 2 was identical to the pilot study scenario, except for the RR signage at the crossings. There were four unique crossings in a lap, and each track consisted of three laps. The crossing notification auditory warning consisted of an Earcon (two dings) followed by a verbal message of "railroad crossing ahead; look left and right". All participants experienced one track with the IVAAs, and one track without IVAAs to allow for within participant comparisons. The IVAA was presented once the vehicle crosses over the advanced warning sign and RR pavement markings, approximately 5-10 seconds before passing over the RR crossing. 


\subsubsection{Apparatus \\ Driving Simulator}

Figure 13 shows the Driving Simulator, a mid-fidelity National Advanced Driving Simulator (NADS) MiniSim version 2.2. The simulation software runs on a single computer, running Microsoft Windows 7 Pro on an Intel Core i7 processor, $3.07 \mathrm{GHz}$ and 12 GB of RAM, and relays sound through a 2.1 audio system. Three Panasonic TH42PH2014 42" plasma displays with a 1280x800 resolution each allow for a 130 degree field of view in front of the seated participant. The center monitor is 28 inches from the center of the steering wheel and the left and right monitors are 37 inches from the center of the steering wheel. The MiniSim also includes a real steering wheel, adjustable car seat, gear-shift, and gas and brake pedals, as well as a Toshiba Ltd. WXGA TFT LCD monitor with a $1280 \times 800$ resolution to display the speedometer, etc. Environmental sound effects are also played through two embedded speakers. These sounds included engine noise, brake screech, turn indicators, collisions, auditory alerts, etc. In the present experiment, all participants experienced the same pre-defined route and properties for the driving task.

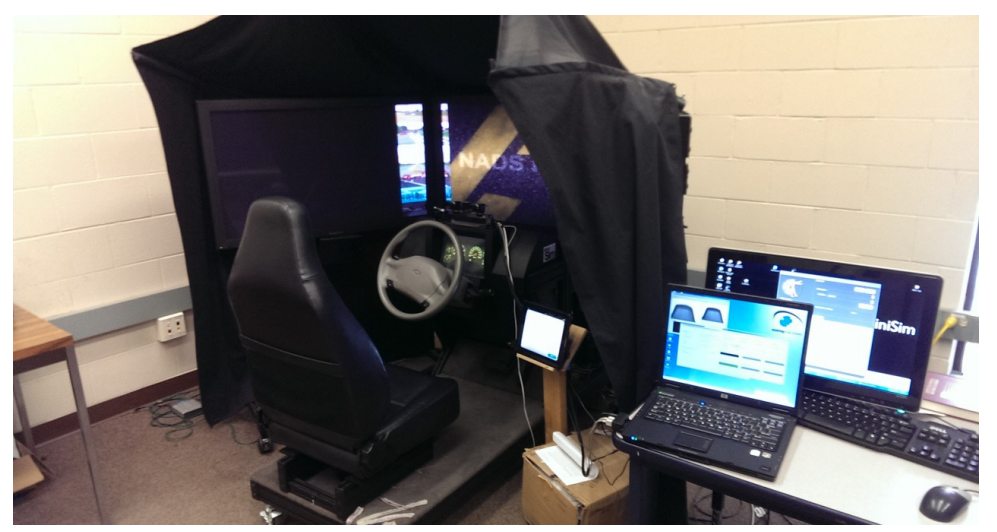

Figure 13. Equipment setup, featuring the NADS simulator, and a laptop for recording the two webcams. 


\subsubsection{Design and Procedure}

A 2x2x4 (Group X IVAAs X Crossing Type) mixed factorial design was

implemented. Participants were randomly assigned to either group A or B before arriving in the lab. The only difference between groups was the presentation order (Table 4);

Group A experienced one track without IVAAs, then the same track a second time with IVAAs. Group B experienced one track with IVAAs, and then the same track a second time without IVAAs. Within subject comparisons were used to measure the difference in compliance scores with and without IVAAs. Between groups comparisons were used to test for an order effect. Participants drove three laps around the course twice for a total of 24 crossing observations (6 YIELD, 6 STOP, 6 crossbuck only, 6 gate protected crossings). Regardless of the group conditions, a train was present only on the $23^{\text {rd }}$ crossing (full gate).

Two webcams recorded the participant's face and driving scenario to measure visual scanning behavior. Vehicle speed and pedal positions were extracted from the simulator for additional compliance behavior analysis (accelerator pedal release, brake pedal force, and vehicle velocity). Following the two simulated tracks participants completed a questionnaire comprised of demographic questions, rail crossing signage knowledge and experience questions, as well as questions probing the perceived utility and preference of the auditory warnings. The entire session lasted one hour: two twenty minute tracks followed by a 10 minute exit interview and RR knowledge questionnaire. 


\subsection{Main Study 2 Results}

As a reminder to the reader, see table 6 for the compliance coding scheme wherein compliance score is a four point scale of binary variables featuring both visual scanning and driving behavior. Table 7 describes each group's order of presentation of IVAA absent and present tracks.

Table 7. Group and track order in relation to IVAA presence and absence.

\begin{tabular}{|c|c|c|}
\hline & Track 1 & Track 2 \\
\hline Group A & No IVAAs & IVAAs \\
\hline Group B & IVAAs & No IVAAs \\
\hline
\end{tabular}

Figure 14 depicts compliance scores for each group over the entire duration of the study. Visually, compliance for tracks with IVAAs (Group B track 1, Group A track 2) are higher than tracks without IVAAs (Group A track 1, Group B track 2). Group B's track 2 scores remain increased even after the IVAAs are removed, suggesting a presentation order effect.

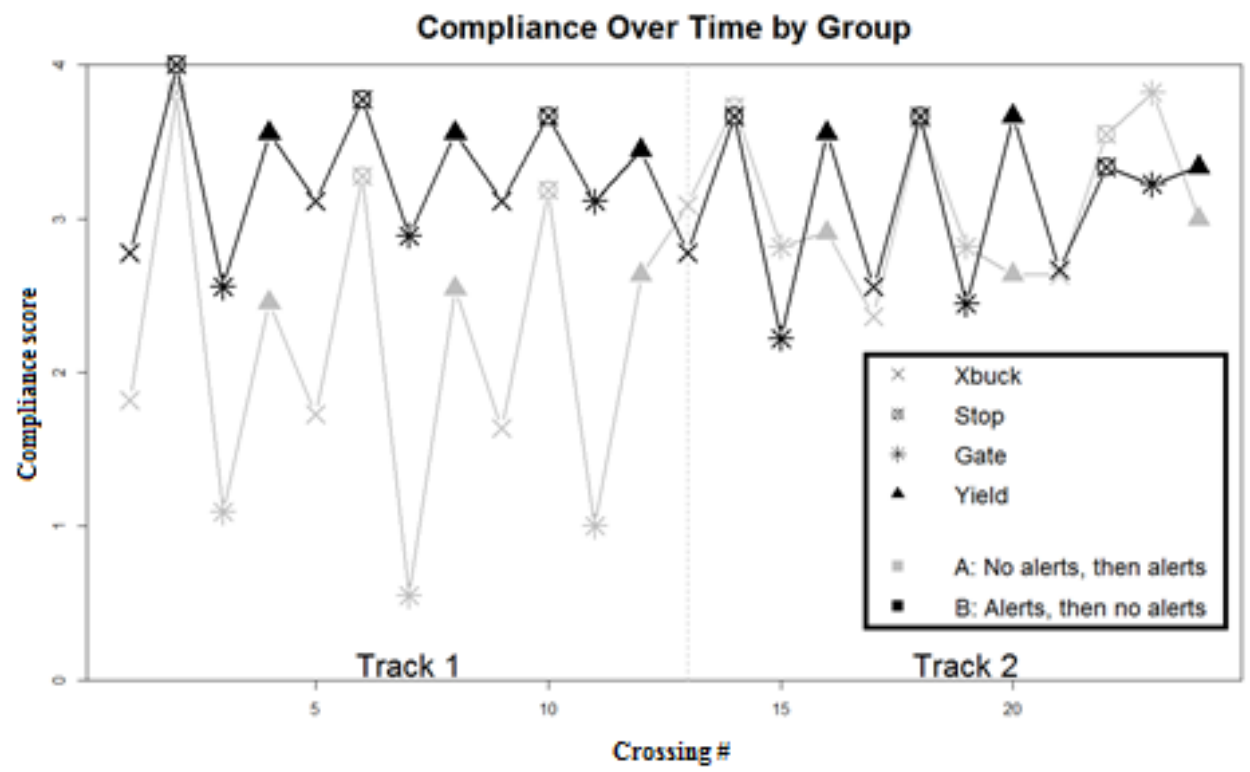

Figure 14. Visual compliance rates for crossings over time, with and without auditory alerts. 
I conducted a $2 \times 2 \times 4$ repeated measures factorial ANOVA to investigate the main effects of the three independent variables (Presentation order, IVAA presence, and crossing sign type) on compliance scores (Table 8). Presentation order (Group) has two levels, IVAAs present on the second track (Group A) or first track (Group B). IVAA has two levels, present, or absent. Crossing type has four levels, crossbuck (Xbuck), STOP, YIELD, and gate. There was a significant main effect of presentation order on compliance score $F(1,18)=5.441, p=.0315$, indicating a significant difference between Group A $(M=2.61, S D=1.24)$, and Group B $(M=3.19, S D=1.09)$. There was a significant main effect of IVAA presence on compliance score $F(1,19)=15.25, p<.001$, indicating that a significant difference between IVAA absence $(M=2.57, S D=1.39)$ and presence $(M=3.179, S D=.908)$. There was a significant main effect of crossing type on compliance score $F(3,54)=23.93, p<.001$, indicating a significant difference between gate $(M=2.34, S D=.1 .29)$, STOP $(M=3.6, S D=.484), \mathrm{YIELD}(M=3.06, \mathrm{SD}=.958)$, and Xbuck $(M=2.49, S D=.909)$. There was also a significant interaction effect for IVAA presence and crossing type on compliance score $F(3,57)=9.674, p<.001$, depicted in Figure 15. 
Table $8.4 \times 2 \times 2$ Repeated measures ANOVA results

\begin{tabular}{|lccccc|}
\hline \multicolumn{7}{|c|}{ Group (2) X IVAA (2) X Type (4) } & ANOVA & \\
& df & Sum Sq & Mean Sq & F & $\begin{array}{c}\text { Sig. } \\
\mathbf{p}=.05\end{array}$ \\
\hline Between & & & & & \\
Group & 1 & 13.36 & 13.359 & 5.441 & $.0315^{*}$ \\
Residuals & 18 & 44.2 & 2.45 & & \\
\hline Within & & & & & \\
IVAA presence & 1 & 14.8 & 14.803 & 20.05 & $0.0002^{*}$ \\
Residuals & 19 & 14.03 & 0.738 & & \\
Crossing Type & 3 & 39.74 & 13.25 & 25.92 & $<.0001^{*}$ \\
Residuals & 57 & 30.31 & 0.53 & & \\
\hline IVAA:Type & 3 & 8.94 & 2.97 & 10.49 & $<.0001^{*}$ \\
Residuals & 57 & 16.14 & 0.28 & & \\
\hline
\end{tabular}

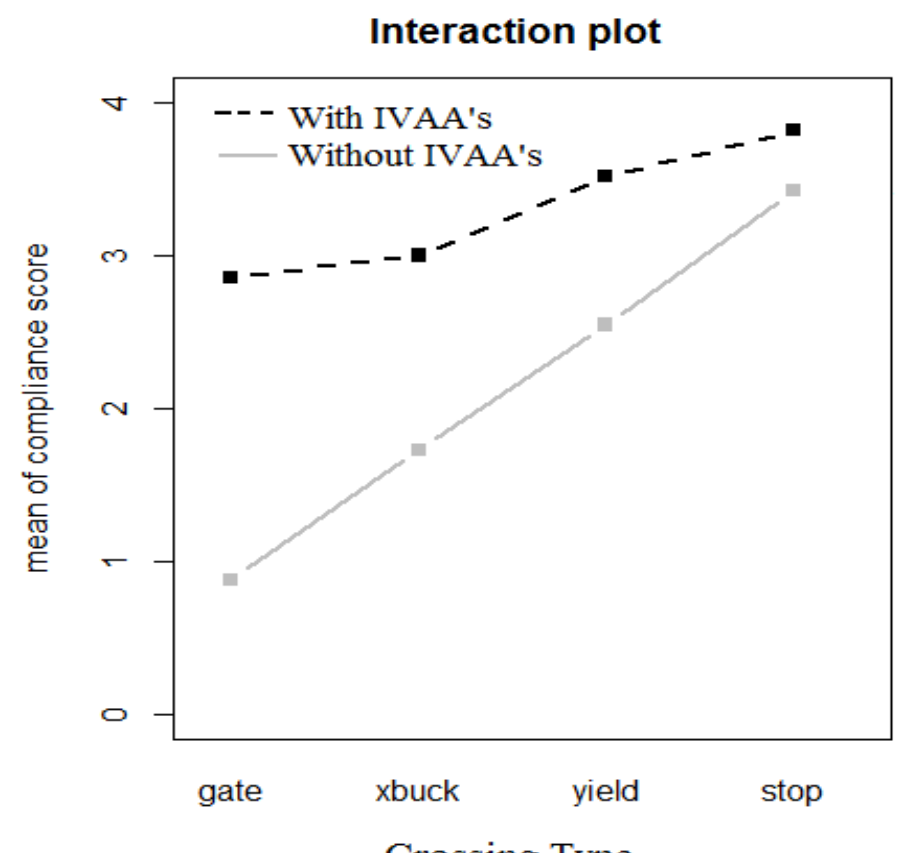

Figure 15. Interaction plot for the effects of crossing warning type and IVAA presentation on compliance scores.

Visually, Group A's Track 1 mean score is lower than all other tracks (Figure 16).

This suggests that not only did the IVAAs improve compliance in general, Group B's

Track 2 mean compliance score remained elevated even after removing IVAAs. To 
compare all four independent combinations of Group (A \& B), and Track (1 \& 2), I ran a post-hoc Tukey HSD tests on the compliance scores (Table 9).

\section{Compliance score by group and track}

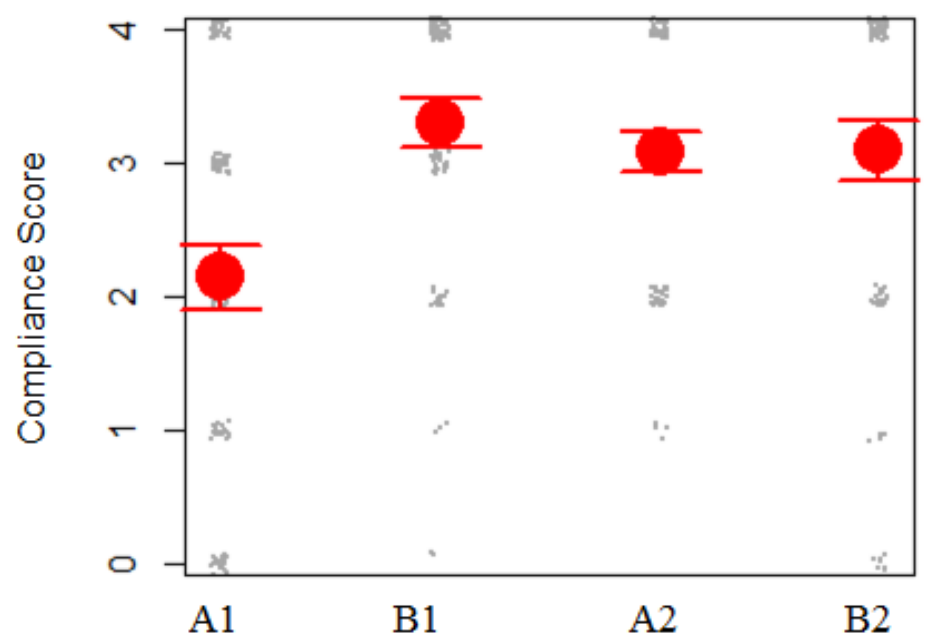

Figure 16. Compliance scores by Group and track number. Group means are the large red circle, error bars are 95\% confidence intervals. Grey dots represent raw compliance scores.

Results of the post-hoc Tukey HSD indicate that Group A's track 1 compliance score (no auditory alerts, $M=2.14, S D=1.4$ ) was significantly lower than Group B's track 1 (auditory alerts, $M=3.29, S D=.98$ ) compliance score; $p<.001$. Group A's track 1 scores (no alerts, $M=2.14, S D=1.4$ ) are also significantly lower than Group B's track 2 scores (no alerts, $M=3.09, S D=1.19$ ); $p=.031$. There was no significant difference between Group B's track 1 score $(M=3.29, S D=.98)$ and Group A's track 2 score $(M=$ $3.08, S D=.83) ; p=.945$. There was also no significant difference between Group A's track 2 score $(M=3.08, S D=.83)$ and Group B's track 2 score $(M=3.29, S D=.98) ; p$ $=.075$. 
Table 9. Post-hoc Tukey Honest Significant Differences for multiple comparisons

\begin{tabular}{|c|c|c|c|c|c|}
\hline \multirow[t]{2}{*}{$\begin{array}{c}\text { Group } \\
\text { comparison }\end{array}$} & \multirow[t]{2}{*}{$\begin{array}{c}\text { Mean } \\
\text { difference }\end{array}$} & \multicolumn{2}{|c|}{$\begin{array}{c}95 \% \\
\text { Confidence } \\
\text { Interval } \\
\end{array}$} & \multirow[t]{2}{*}{$\mathrm{p}<.05$} & \multirow{2}{*}{$\begin{array}{c}\text { Cohen's } \\
\text { d }\end{array}$} \\
\hline & & Lower & Upper & & \\
\hline A1-B1 & -1.15 & -1.72 & -0.58 & $<.001 *$ & 0.93 \\
\hline A1-B2 & -0.94 & -1.52 & -0.38 & $.001 *$ & 0.72 \\
\hline B1-A2 & 0.21 & -0.35 & 0.78 & 0.76 & 0.23 \\
\hline B2-A2 & 0.01 & -0.56 & 0.58 & 0.81 & 0 \\
\hline
\end{tabular}

I then ran two paired samples t-tests to compare the mean difference between tracks 1 and 2 within both groups (Table 10). Compliance scores were significantly higher in track 2 (alerts, $M=3.08, S D=.83$ ) than track 1 (no alerts, $M=2.14, S D=1.40$ ) for Group A; $t(10)=-5.38, p=.0003$. This comparison is of particular importance, as it is the only true within subjects comparison including "natural driving behaviors" before exposure to IVAAs (Group B's “no IVAA” track 2's performance may have been contaminated by their previous exposure to IVAAs). There was no significant difference between track 2 (no alerts, $M=3.09, S D=1.19$ ) and track 1 (alerts, $M=3.30, S D=.98$ ) for Group B, confirming that not only did the IVAAs improve compliance, but they had a lasting effect on Group B after being removed in Track $2 ; t(8)=1.74, p=.12$. The lasting effect suggests that drivers are willing to comply, but may not know exactly how to comply with the variety of RR visual warning types. 
Table 10. Results of paired samples t-tests for track 1 and track 2

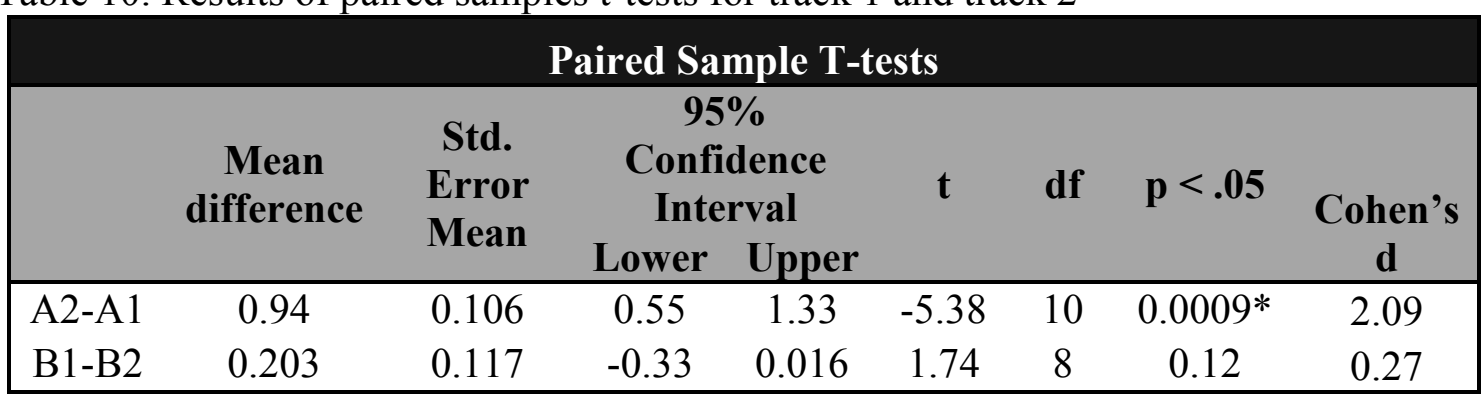

Analyzing each type of crossing separately reveals additional patterns in compliance behavior (Figure 17). Compliance without IVAAs is lowest for the crossing protected by an active gate, followed by a crossbuck. Compliance is higher for the more novel combinations of a crossbuck with a STOP sign, or a crossbuck with a YIELD sign. IVAAs had the largest effect on gated crossings, and the smallest effect on STOP and YIELD signed crossings.

\section{Compliance by sign type}

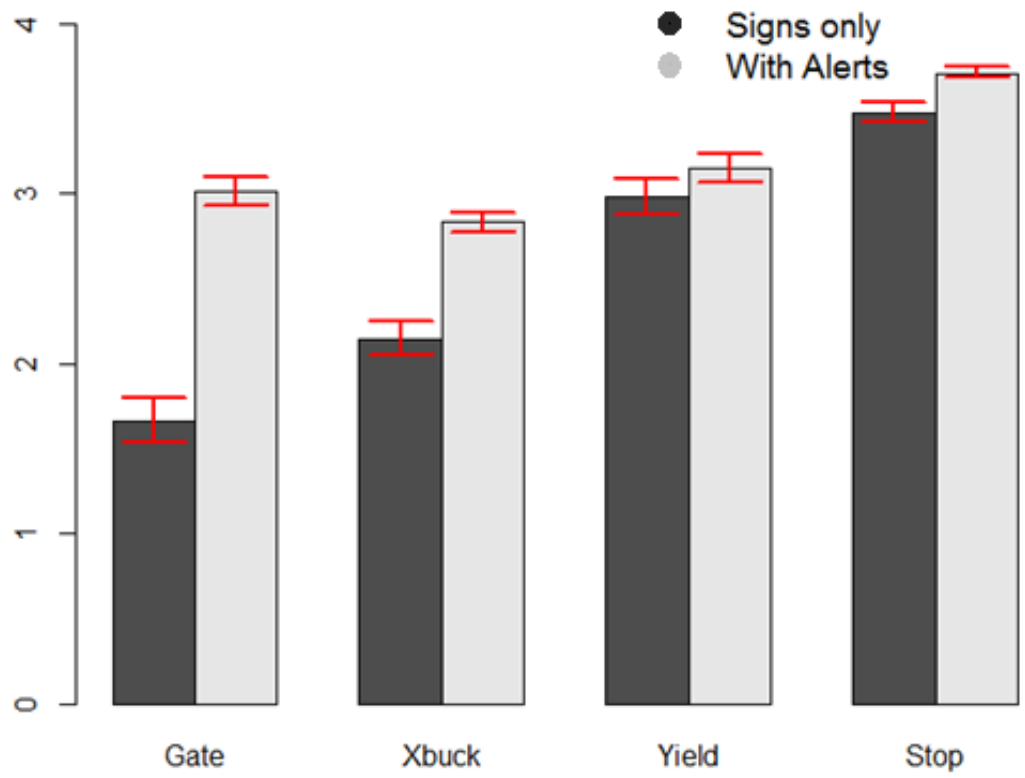

Figure 17. Compliance scores for each sign type with and without IVAAs. Error bars represent $95 \%$ confidence intervals. 
I ran four paired samples t-tests using a Bonferroni correction (with adjusted alpha level $=0.0125: 0.05 / 4$ pairs) to compare the difference in compliance scores for each crossing type with and without IVAAs (Table 11). There was a significant increase in compliance scores between crossbucks only $(M=2.15, S D=1.04)$ and crossbucks with IVAAs $(M=2.83, S D=.61) ; t(19)=-4.2, p<.0001$. Using the adjusted alpha level, there was no significant increase in compliance scores between STOP only $(M=$ $3.48, S D=.59)$ and STOP with IVAAs $(M=3.72, S D=.33) ; t(19)=-2.27, p=.035$. There was a significant increase in compliance scores between Gates only $(M=1.67, S D$ $=1.32)$ and Gates with IVAAs $(M=3.02, S D=.83) ; t(19)=-4.69, p<.0001$. The was no significant increase between YIELD $(M=2.98, S D=1.08)$ and YIELD with IVAAs $(M=3.15, S D=.83) ; t(19)=-.84, p=.412$. All other combinations of comparisons between visual warning types are presented in Table 12. I ran paired samples t-tests using a Bonferroni correction (with adjusted alpha level $=0.0042: 0.05 / 12$ pairs).

Table 11. Post-hoc paired samples t-tests with a Bonferroni correction for the different visual warnings with \& without IVAAs

\begin{tabular}{|lcccccccc|}
\hline \multicolumn{7}{c|}{ Post-hoc Paired Samples Tests } \\
\hline \multicolumn{7}{c|}{ Paired Differences } \\
\hline $\begin{array}{c}\text { With alerts - } \\
\begin{array}{c}\text { Without } \\
\text { alerts }\end{array}\end{array}$ & $\begin{array}{c}\text { Mean } \\
\text { difference }\end{array}$ & $\begin{array}{c}\text { Std. } \\
\text { Error } \\
\text { Mean }\end{array}$ & $\begin{array}{c}\text { 95\% Confidence } \\
\text { Interval }\end{array}$ & t & df & $\begin{array}{c}\text { sig. } \\
\text { p <.0125 } \\
\text { adjusted }\end{array}$ & $\begin{array}{c}\text { Cohen's } \\
\text { d }\end{array}$ \\
\hline Xbucks & 0.683 & 0.203 & 0.296 & 1.07 & 3.69 & 19 & $.001^{*}$ & 0.8 \\
STOP & 0.3 & 0.108 & 0.069 & 0.531 & 2.71 & 19 & .014 & 0.49 \\
Gates & 1.417 & 0.288 & 0.805 & 2.028 & 4.85 & 19 & $.0001^{*}$ & 1.2 \\
YIELD & 0.267 & 0.214 & -0.173 & 0.706 & 1.26 & 19 & 0.22 & 0.17 \\
\hline
\end{tabular}


Table 12. Post-hoc paired T-test for all other sign type comparisons

\begin{tabular}{|c|c|c|c|c|}
\hline \multicolumn{5}{|c|}{ All mixed sign type paired comparisons } \\
\hline \multirow[t]{2}{*}{$\begin{array}{l}\text { Sign type } \\
\text { comparison }\end{array}$} & \multirow[t]{2}{*}{$\begin{array}{c}\text { Mean } \\
\text { difference }\end{array}$} & \multicolumn{2}{|c|}{$\begin{array}{c}95 \% \\
\text { Confidence } \\
\text { Interval }\end{array}$} & \multirow{2}{*}{$\begin{array}{c}\quad \text { sig } \\
\mathbf{p}<.0042 \\
\text { adjusted }\end{array}$} \\
\hline & & Lower & Upper & \\
\hline \multicolumn{5}{|c|}{ Without alerts } \\
\hline YIELD - Gate & 1.3 & 0.72 & 1.88 & $<.001^{*}$ \\
\hline STOP - Gate & 1.81 & 1.24 & 2.39 & $<.001^{*}$ \\
\hline YIELD - Xbuck & 0.78 & 0.21 & 1.36 & $0.001 *$ \\
\hline STOP - Xbuck & 1.3 & 0.72 & 1.87 & $<.001 *$ \\
\hline STOP - YIELD & 0.51 & -0.06 & 1.09 & 0.11 \\
\hline Xbuck - Gate & 0.51 & -0.06 & 1.09 & 0.11 \\
\hline \multicolumn{5}{|c|}{ With alerts } \\
\hline YIELD - Gate & 0.15 & -0.42 & 0.72 & 0.99 \\
\hline STOP - Gate & 0.7 & 0.12 & 1.27 & 0.005 \\
\hline YIELD - Xbuck & 0.36 & -0.21 & 0.94 & 0.52 \\
\hline STOP - Xbuck & 0.91 & 0.34 & 1.49 & $<.001 *$ \\
\hline STOP - YIELD & 0.55 & -0.02 & 1.12 & 0.07 \\
\hline Xbuck - Gate & -0.21 & -0.79 & 0.36 & 0.94 \\
\hline
\end{tabular}

These comparisons show that compliance without IVAAs is naturally higher for the newer RR visual warnings (Xbuck and STOP sign, Xbuck and YIELD sign). This supports the FRA's decision to transition away from crossbucks by themselves, favoring the combination crossbucks with YIELD or STOP signs.

For descriptive statistics on relevant questions from the post-session survey, see Figure 18. Participants in general found the IVAAs more helpful than annoying. Sixteen out of twenty participants reported that they would be willing to use this type of system in their own vehicles, especially in unfamiliar areas. The remaining four participants thought the crossing notifications were annoying or unnecessary. 


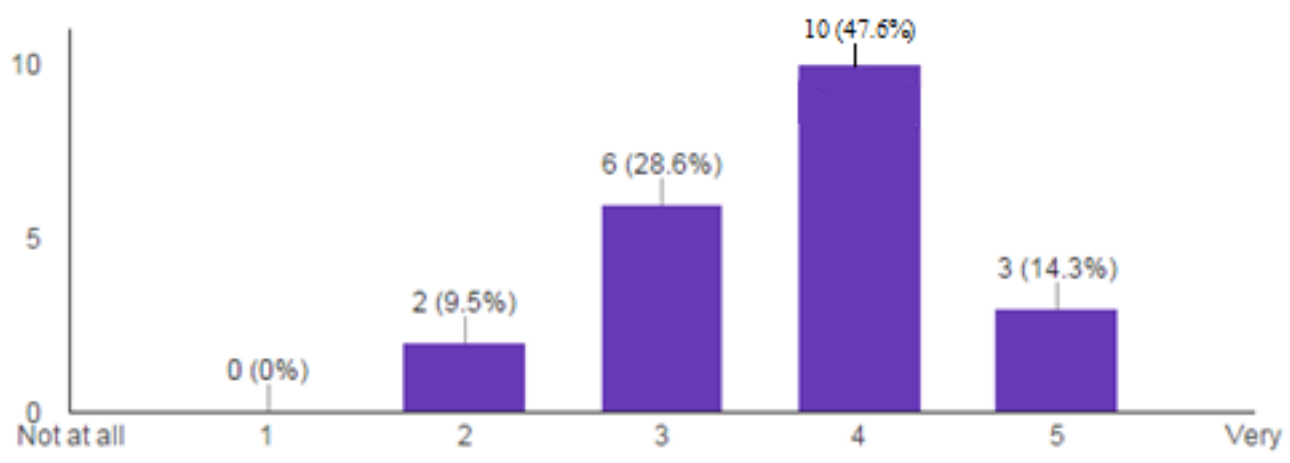

\section{How annoying was the auditory display?}

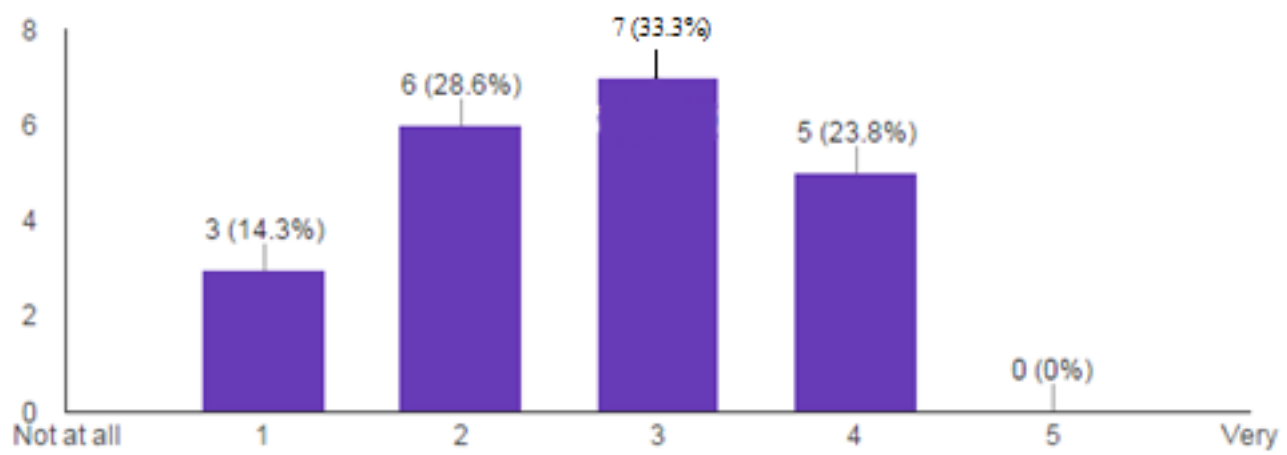

Figure 18. Subjective results on the perceived helpfulness and annoyingness of the IVAAs.

Finally, all but two participants made a complete stop at the 23 rd crossing when the train was present. Both of those participants were in group B's track 2, where IVAAs were not present. Both participants reported that from their perspective, they were going too fast to come to a full stop at a safe distance in front of the lowering gate arm.

\subsection{Discussion of Study 2}

Results show that IVAAs significantly improve compliance at both passive and active grade level railroad (RR) crossings, supporting my main hypothesis. This is most likely due to the information embedded in the IVAA instructing the participant on how to comply. Compliance is lowest for the gated crossings for both IVAA present and absent 
conditions. This is not surprising, as active warnings in the "off" position are used by the participant as a cue that there is no train approaching, and thus, no danger or reason to look.

Compliance behaviors are also fairly consistent across participants for each warning type, which manifests as the repetitive four crossing pattern in compliance scores depicted in Figure 12. Group B's track 2 (no IVAAs) compliance scores are not significantly different than their track 1 scores (with IVAAs). This shows promise that even after the IVAA are removed, the participants remained primed to visually scan for trains, and remember the expected behavior at passive crossings. Once participants are primed and trained on how to behave on approach to RR crossings, their compliance behavior remains high even after removing the IVAAs. How long the novelty of these IVAAs will last is currently unknown, and worthy of a follow up longitudinal study. Drivers may habituate to these warnings just as they have habituated to passive signage after years of repeated exposure.

Compliance for STOP protected crossings were fairly high regardless of IVAAs. There are two possible explanations. The first is that STOP signs are not ambiguous; drivers understand exactly what they are expected to do. The second explanation could be that visual scanning behavior comprised half of the total compliance score. Participants rarely come to a complete stop at an intersection and neglect to visual scan for oncoming traffic. Whether the participants were actually checking around the corner to search for trains or simply rotating their head out of habit is unclear from the recorded videos of the participant's face. 
Compliance for the two novel types of visual warnings (Xbuck + STOP, Xbuck + YIELD) are significantly higher than the two classic signage (Xbuck only, full gate). This is most likely due to the obvious meaning associated with the more familiar standard highway intersection signage. Participants experience much more STOP and YIELD signs in their daily lives, and are more properly trained about their meanings during driver's education. Participants need less instruction on how to comply at these types of crossings. This supports the recent push by the FRA to include either a STOP or YIELD sign at all passive crossings by the year 2019. However, as other researchers have pointed out, we must exhibit caution when placing STOP signs at intersections that may not warrant a complete stop. At crossing with low volumes of train traffic, a stop sign might be interpreted as a "false alarm", which encourages non-compliance.

Subjective results suggest that around $75 \%$ (16) of the twenty participants would opt in to using this type of IVAA crossing notification system, especially in unfamiliar areas. In the RR knowledge portion of the survey, the majority of participants (12/20) were misinformed or unsure of the appropriate behavior in response to raised gates and crossbucks without any additional STOP or YIELD signs. Many participants indicated that they are more likely to look for a train at active crossings because it is unlikely that a train would arrive at passive crossings. However true this is, assuming that trains are not likely to be present at passive crossings could lead to dangerous behaviors, and could help explain the majority of collisions that occur at passive crossings.

A few participants expressed concerns that the IVAAs could become annoying after repeated exposure. More attempts could be made to make more aesthetically pleasing sounds as the IVAAs, however I believe that the actual acoustic characteristics 
of the alert is not the primary reason some participants found it annoying. The notification only system does not contain the one piece of information all drivers are looking for when approaching a RR crossings: is a train present or not. Participants indicated that they would be much more willing to use the IVAA system if it contained train present/absent information.

\section{Conclusion}

Based on the results of the main Study 2, IVAAs show promise in increasing compliance at grade railroad (RR) crossings. The IVAAs I provided to the participants reminded (or perhaps informed) participants to visually scan in both directions to search for a train when approaching a crossing. Perhaps the training received in driver's education fails to instill into younger drivers the expected behaviors when approaching RR crossings. Perhaps drivers simply need a reminder of the dangers posed at every rail crossing, as suggested by the lasting effects of the IVAAs in group B's track 2 performance. With all else being equal, increasing compliance at RR crossings should decrease the rate of train-vehicle collisions.

A system similar to the one tested in study 2 could be implemented with the current hardware in vehicles (smartphones, in-vehicle GPS's, etc.,) and data sets (RR crossing location coordinates) already made public by the FRA. A simple mobile application could be designed to generate an IVAA whenever the device detects that it is in the vicinity of a RR crossing. This simple app would be able to upgrade all crossings in the US to be more salient at a fraction of the cost of installing hardware at each crossing. The cost of this system would be orders of magnitude less expensive than previously 
predicted (Ogden, 2007, Table 1), due to the exponential increase in the number of drivers using GPS tracking devices in their vehicle over previous decades.

Improved compliance in response to IVAAs will have the largest effect on reducing collisions at passive crossings. Low saliency is the leading cause of accidents at passive crossings, which manifests as the driver's failure to detect an oncoming train or crossing. Including IVAAs would remedy this issue of saliency by presenting an "active" auditory warning, attracting attention but not visually distracting the driver.

I predicted that IVAAs may do little to increase the compliance rates at active crossings in the long term. Since the driver relies on the state of the active warning as the primary cue, I assumed adding an additional ambiguous warning such as "crossing ahead" would do little to change their behavior. However, the result from Study 2 suggest that IVAAs actually encourage drivers to visually scan at gated crossings, even if the gate arm is in the "up" position. IVAAs may not have any effect on intentional noncompliance such as gate- running, which is one of the main causes of collisions at active crossings. One strategy that might discourage gate-running is to utilize spatial sounds from inside the vehicle to augment the driver's distance perception of the train.

Another issue that IVAAs would solve is the noise pollution added to the environment by wayside horns. By using an auditory warning instead of a wayside horn the auditory warning is contained within the driver's vehicle, not dispersed in all directions inconveniencing those that work and live in the surrounding area. However, the one caveat is that wayside horns should not and will not be replaced until all vehicles are equipped with the capability to present these IVAAs, and we find an alternative warning system for pedestrians and bicyclists. IVAAs would also solve the issue of a 
driver's failure to detect a train horn due to the level of noise inside the vehicle.

Presenting the auditory alerts inside the vehicle also improve compliance in quiet zones and whistle-banned areas, allowing for more salient warnings in the areas with noise restrictions.

Perhaps the largest benefit of IVAAs is the implied reminder that trains could be present even at passive crossings. A significant portion of participants in study 2 reported that they are less likely to worry about trains at passive crossings because in their experience, trains "only" use crossings protected by active warnings (gates, lights, etc.). This extremely dangerous line of thinking that contributes to the lack of compliance at passive crossings, and perhaps were IVAAs would have the largest impact.

The next logical step in reducing the number of train-vehicle collisions down towards zero would be to develop this type of crossing notification IVAA mobile application, and deploy it to a large sample of drivers. Based a combination of objective measures and subjective feedback, the functionality and display of the IVAA system could be redesigned to better serve the general population. A longitudinal study could also help determine for how long these IVAAs will be effective before drivers start to habituate to them, as they have already done to the passive visual warnings. Finally, for as long as the warning fails to provide the one piece of information the driver needs when approaching the crossing (is a train present, or not), driver's may continue to learn to ignore whatever passive warnings we present to them. 


\section{References}

Abraham, J., Datta, S., and Datta, T.K. (1998). Driver behavior at rail-highway crossings. Transportation Research Record: Journal of the Transportation Research Board, $1648,28-34$.

Baldwin, C. L., \&. Lewis, B. A. (2014). Perceived urgency mapping across modalities within a driving context. Applied Ergonomics, 45, 1270-1277.

Benekohal, R.F. and Rawls, C.G. (2004a). Analyses of the Motorists' Responses in Final Surveys to the In-Vehicle Receiver (IVR) (FHWA-IL/UI-TOL-13). Urbana, IL: University of Illinois at Urbana-Champaign.

Benekohal, R.F. and Rawls, C. G. (2004b). Analyses of the Motorists' Responses (in Survey Number 2) to the In-Vehicle Receiver (IVR) After Experiencing One Mode of Operation (FHWA-IL/UI-TOL-11). Urbana, IL: University of Illinois at Urbana-Champaign.

Bowman, B.L. (1989). Analysis of railroad-highway crossing active advance warning devices. Transportation Research Record: Journal of the Transportation Research Board, 1114. 141-151.

Burnham, A. (1995). Stop sign effectiveness at railroad grade crossings (abuse without excuse). Third International Symposium on Railroad-Highway Grade Crossing Research and Safety.

Coleman, F., \& Venkataraman, K. (2001). Driver behavior at vehicle arresting barriers: Compliance and violations during the first year at the McLean site. Transportation Research Record: Journal of the Transportation Research Board, (1754), 68-76. 
Cooper, D. L., \& Ragland, D. R. (2007). Driver behavior at rail crossings: cost-effective improvements to increase driver safety at public at-grade rail-highway crossings in California. Safe Transportation Research \& Education Center.

Cummings, M. L. (2004, September). Automation bias in intelligent time critical decision support systems. AIAA 1st Intelligent Systems Technical Conference, 557-562.

Cvach, M. (2012). Monitor alarm fatigue: an integrative review. Biomedical Instrumentation \& Technology, 46(4), 268-277.

Dingler, T., Lindsay, J., \& Walker, B. N. (2008). Learnabiltiy of sound cues for environmental features: Auditory icons, earcons, spearcons, and speech. In Proceedings of the International Conference on Auditory Display (ICAD).

Federal Highway Administration (2009) Manual of Uniform Traffic Control Devices. Washington D.C.

Godley, S.T., Triggs, T.J., Fildes, B.N., 2002. Driving simulation validation for speed research. Accident Analysis and Prevention 34, 589-600.

Graham, R. (1999). Use of auditory icons as emergency warnings: evaluation within a vehicle collision avoidance application. Ergonomics, 42(9), 1233-1248.

Hellier, E., Edworthy, J., Weedon, B., Walters, K., \& Adams, A. (2002). The perceived urgency of speech warnings: Semantics versus acoustics: The Journal of the Human Factors and Ergonomics Society, 44(1), 1-17.

icc.illinois.gov/ilol/ (retrieved 8/13/2015) 
Leibowitz, H. W. (1985). Grade Crossing Accidents and Human Factors Engineering. American Scientist, 73, 558-562.

Lenné, M. G., Rudin-Brown, C. M., Navarro, J., Edquist, J., Trotter, M., \& Tomasevic, N. (2011). Driver behaviour at rail level crossings: Responses to flashing lights, traffic signals and stop signs in simulated rural driving. Applied ergonomics, 42(4), 548-554.

Lerner, N.D., Llaneras, R.E., McGee, H.W., and Stephens, D.E. (2002) Traffic-Control Devices for Passive Railroad-Highway Grade Crossings. Nation Cooperative Highway Research Program (NCHRP) Report 470. Washing, D.C.: Transportation Research Board.

Lerner, N.D., Ratte, D., \& Walker, J. (1990). Driver Behavior at Rail-Highway Crossings. US Department of Transportation, Federal Highway Administration. Report No. FHWA-SA-90-008, Washington, DC.

McCollister, G. M., \& Pflaum, C. C. (2007). A model to predict the probability of highway rail crossing accidents. Proceedings of the Institution of Mechanical Engineers, Part F: Journal of rail and rapid transit, 221(3), 321-329.

McGookin, D. K., \& Brewster, S. A. (2004). Empirically derived guidelines for the presentation of concurrent Earcons. Proceedings of BCS HCI, 65-68.

Mok, S. C., \& Savage, I. (2005). Why Has Safety Improved at Rail-Highway Grade Crossings?. Risk Analysis, 25(4), 867-881. 
Mueller, S. T. \& Piper, B. J. (2014). The Psychology Experiment Building Language (PEBL) and PEBL Test Battery. Journal of Neuroscience Methods, 222, 250-259.

Ngamdung, T., \& daSilva, M. (2013). Driver Behavior Analysis at Highway-Rail Grade Crossings using Field Operational Test Data—Light Vehicles (DOT-VNTSCFRA-12-02).

Noyce, D., \& Fambro, D. (1998). Enhanced traffic control devices at passive highwayrailroad grade crossings. Transportation Research Record: Journal of the Transportation Research Board, (1648), 19-27.

Office of the Inspector General (2005). Audit Of Oversight Of Highway Rail Grade Crossing Accident Reporting, Investigations, And Safety Regulations (Report Number: MH-2006-016). Washington, D.C.: Federal Railroad Administration.

Ogden, B. D. (2007). Railroad-highway grade crossing handbook. Revised 2nd ed. U.S. Department of Transportation Report, FHWA-TS-86-215.

Oli.org (retrieved 8/13/2015)

Raub, R.A. (2006). Examination of highway-rail grade crossing collisions over 10 years in seven Midwestern states. ITE Journal, 76(4), 16-26

Richards, S. H., \& Heathington, K. W. (1990). Assessment of warning time needs at railroad-highway grade crossings with active traffic control. Transportation Research Record, (1254). 
Richards, S. H., Heathington, K. W., \& Fambro, D. B. (1990). Evaluation of constant warning times using train predictors at a grade crossing with flashing light signals. Transportation Research Record, 1254.

Russell, E. R., \& Burnham, A. (1999). A Review of Past and Present Research, Guidelines and Practice for the Proper Use of Stop Signs at Rail-Highway Grade Crossings. Enhancing Transportation Safety in the 21st Century ITE International Conference.

Russell, E. R., \& Kent, W. D. (1993, December). Two human factors studies to evaluate new passive devices at rail-highway grade crossings and a comparison to traditional traffic study methods. International Symposium on Railroad-Highway Grade Crossing Research and Safety, 2nd, 1992, Knoxville, Tennessee, USA.

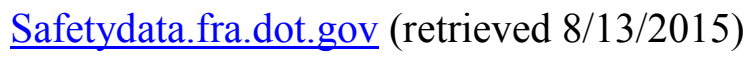

Sanders, M.S., and McCormick, E.J. Human Factors in Engineering and Design, Sixth Edition. McGraw-Hill, New York, 1987.

Searle, A., Di Milia, L., \& Dawson, D. (2012). An investigation of risk-takers at railway level crossings.

Sööt, S., Metaxatos, P., \& Sen, A. (2004). Accident trends and safety devices at highwayrail grade crossings. Motor cycle, 2, 2-897.

Triggs, T.J., (2002). Driving simulation for railway level-crossing research. Proceedings of the Seventh International Symposium on Railroad-High Grade Crossing 
Research and Safety: "Getting Active at Passive Crossings", Melbourne, Australia.

Weiland, R., \& Woll, T. (2002). Challenges and opportunities for ITS standards at highway-rail intersections. Proceedings Getting Active at Passive Crossings: Seventh International Symposium on Railroad-Highway Grade Crossing Research and Safety. Melbourne, Australia: Monash University.

Yan, X., Han, L. D., Richards, S., \& Millegan, H. (2010). Train-Vehicle Crash Risk Comparison Between Before and After Stop Signs Installed at Highway-Rail Grade Crossings. Traffic injury prevention, 11(5), 535-542.

Yeh, M., \& Multer, J. (2008). Driver behavior at highway-railroad grade crossings: a literature review from 1990-2006 (DOT/FRA/ORD-08/03). 